\title{
Spatiotemporal expression patterns of Pax6 in the brain of embryonic, newborn, and adult mice
}

\author{
Deyi Duan $^{1} \cdot$ Yuhong $\mathrm{Fu}^{1} \cdot$ George Paxinos $^{1,2} \cdot$ Charles Watson $^{1,3, *}$ \\ 1. Neuroscience Research Australia, Randwick, Sydney, NSW 2031, Australia \\ 2. School of Medical Science, University of New South Wales, Sydney, NSW 2052, Australia \\ 3. Faculty of Health Sciences, Curtin University, Shenton Park Health Research Campus, GPO Box U1987, Perth, \\ WA 6845 , Australia \\ * To whom correspondence should be addressed, c.watson@curtin.edu.au
}

\begin{abstract}
The transcription factor Pax6 has been reported to specify neural progenitor cell fates during development and maintain neuronal commitments in the adult. The spatiotemporal patterns of Pax6 expression were examined in sagittal and horizontal sections of the embryonic, postnatal, and adult brains using immunohistochemistry and double immunolabeling. The proportion of Pax6-immunopositive cells in various parts of the adult brain was estimated by using the isotropic fractionator methodology. It was shown that at embryonic day 11 (E11) Pax6 was robustly expressed in the proliferative neuroepithelia of the ventricular zone in the forebrain and hindbrain, and in the floor and the mesencephalic reticular formation (mRt) in the midbrain. At E12 its expression emerged in the nucleus of the lateral lemniscus in the rhombencephalon and disappeared from the floor of the midbrain. As neurodevelopment proceeds, the expression pattern of Pax6 changes from the mitotic germinal zone in the ventricular zone to become extensively distributed in cell groups in the forebrain and hindbrain, and the expression persisted in the mRt. The majority of Pax6 positive cell groups were maintained until adult life but the intensity of Pax6 expression became much weaker. Pax6 expression was maintained in the mitotic subventricular zone in the adult brain, but not in the germinal region dentate gyrus in the adult hippocampus. There was no obvious colocalization of Pax6 and NeuN during embryonic development, suggesting Pax6 is found primarily in developing progenitor cells. In the adult brain, however, Pax6 maintains neuronal features of some subtypes of neurons, as indicated by $97.1 \%$ of Pax6positive cells co-expressing NeuN in the cerebellum, $40.7 \%$ in the olfactory bulb, $38.3 \%$ in the cerebrum, and $73.9 \%$ in the remaining brain except the hippocampus. Differentiated tyrosine
\end{abstract}


hydroxylase (TH) neurons were observed in the floor of the E11 midbrain where Pax6 was also expressed, but no obvious colocaliztion of TH and Pax6 was detected. No Pax6 expression was observed in TH-expressing areas in the midbrain at E12, E14, and postnatal day 1 . These results support the notion that Pax6 plays pivotal roles in specifying neural progenitor cell commitments and maintaining certain mature neuronal fates.

Keywords Pax $6 \cdot$ mouse $\cdot$ embryonic brain $\cdot$ neural development $\cdot$ adult brain $\cdot$ tyrosine hydroxylase $\cdot \mathrm{NeuN}$

$\begin{array}{ll}\text { Abbreviation List } \\ \text { 3V } & \text { 3rd ventricle } \\ \text { 4V } & \text { 4th ventricle } \\ \text { 5PC } & \text { motor trigeminal nucleus, parvicellular part } \\ \text { AA } & \text { anterior amygdaloid area } \\ \text { Amg } & \text { amygdala } \\ \text { AO } & \text { anterior olfactory nucleus } \\ \text { AOP } & \text { anterior olfactory area posterior part } \\ \text { APT } & \text { anterior pretectal nucleus } \\ \text { BL } & \text { basolateral amygdaloid nucleus } \\ \text { BM } & \text { basomedial amygdaloid nucleus } \\ \text { Cb } & \text { cerebellum } \\ \text { Ce } & \text { central amygdaloid nucleus } \\ \text { ceph } & \text { cephalic flexure } \\ \text { CG } & \text { central gray } \\ \text { Cx } & \text { cortex } \\ \text { DC } & \text { dorsal cochlear nucleus } \\ \text { DG } & \text { dentate gyrus } \\ \text { Dien } & \text { diencephalon } \\ \text { DLL } & \text { dorsal nucleus of the lateral lemniscus } \\ \text { DR } & \text { dorsal raphe nucleus } \\ \text { DTg } & \text { dorsal tegmental nucleus } \\ \text { DTT } & \text { dorsal tenia tecta } \\ \text { ECu } & \text { external cuneate nucleus } \\ \text { EGL } & \text { external granular layer of developing cerebellum } \\ \text { EP } & \text { entopeduncular nucleus } \\ \text { E/OV } & \text { ependymal and subendymal layer/olfactory ventricle } \\ \text { F } & \text { nucleus of the fields of Forel } \\ \text { FovIs } & \text { fovea isthmus } \\ \text { Gi } & \text { gigantocellular reticular nucleus } \\ \text { Gl } & \text { glomerular layer of the olfactory bulb } \\ \text { GP } & \text { globus pallidus } \\ \text { GrC } & \text { granule cell layer of cochlear nuclei } \\ \text { HDB } & \text { nucleus of the horizontal limb of the diagonal band } \\ \text { I } & \text { intercalated nuclei of the amygdala } \\ \text { IEn } & \text { intermediate endopiriform nucleus } \\ \text { InC } & \text { interstitial nucleus of Cajal } \\ \text { IO } & \text { inferior olivary nucleus } \\ \text { Is } & \text { Isthmus } \\ \text { isRt } & \text { isthmic reticular formation }\end{array}$




\begin{tabular}{|c|c|}
\hline JPLH & juxtaparaventricular part of lateral hypothalamus \\
\hline $\mathrm{La}$ & lat amygdaloid nucleus \\
\hline LC & locus coeruleus \\
\hline LD & laterodorsal thalamic nucleus \\
\hline LDTg & laterodorsal tegmental nucleus \\
\hline $\mathrm{LHb}$ & lateral habenular nucleus \\
\hline $\mathrm{Li}$ & linear nucleus \\
\hline LL & nucleus of the lateral lemniscus \\
\hline LP & lateral posterior thalamic nucleus \\
\hline LPO & lateral preoptic area \\
\hline LRt & lateral reticular nucleus \\
\hline LSI & lateral septal nucleus, intermediate part \\
\hline LV & lateral ventricle \\
\hline МCPC & magnocellular nucleus of the posterior commissure \\
\hline $\mathrm{Me}$ & medial amygdaloid nucleus \\
\hline Mesen & mesencephalon \\
\hline $\mathrm{MHb}$ & medial habenular nucleus \\
\hline $\mathrm{MnR}$ & median raphe nucleus \\
\hline $\mathrm{mRt}$ & mesencephalic reticular formation \\
\hline MS & medial septal nucleus \\
\hline MVe & medial vestibular nucleus \\
\hline MVPO & medioventral periolivary nucleus \\
\hline PAG & periaqueductal gray \\
\hline $\mathrm{PaXi}$ & paraxiphoid nucleus of thalamus \\
\hline $\mathrm{pc}$ & posterior commissure \\
\hline PCom & nucleus of the posterior commissure \\
\hline PDTg & posterodorsal tegmental nucleus \\
\hline Pir & piriform cortex \\
\hline PL & paralemniscal nucleus \\
\hline PLH & peduncular part of lateral hypothalamus \\
\hline $\mathrm{Pn}$ & pontine nuclei \\
\hline $\operatorname{PrC}$ & precommissural nucleus \\
\hline PrG & pregeniculate nucleus \\
\hline PrTh & prethalamus (prosomere 3 ) \\
\hline PrThE & prethalamic eminence \\
\hline Ptec & pretectum \\
\hline Rhomb & rhombencephalon \\
\hline Rt & reticular thalamic nucleus \\
\hline $\operatorname{RtTg}$ & reticulotegmental nucleus of the pons \\
\hline $\mathrm{SN}$ & substantia nigra \\
\hline SPFPC & subparafascicular thalamic nucleus, parvicellular part \\
\hline SubG & subgeniculate nucleus \\
\hline SuVe & superior vestibular nucleus \\
\hline Telen & telencephalon \\
\hline $\mathrm{Tu}$ & olfactory tubercle \\
\hline $\mathrm{VC}$ & ventral cochlear nucleus \\
\hline VCA & ventral cochlear nucleus, anterior part \\
\hline VDB & nucleus of the vertical limb of the diagonal band \\
\hline VEn & ventral endopiriform claustrum \\
\hline VP & ventral pallidum \\
\hline VTT & ventral tenia tecta \\
\hline VTA & ventral tegmental area \\
\hline $\mathrm{VZ}$ & ventricular zone \\
\hline $\mathrm{X}$ & nucleus $\mathrm{X}$ \\
\hline ZI & zona incerta \\
\hline
\end{tabular}




\section{Introduction}

Pax6 is a highly conserved transcription factor containing two N-terminally located DNA binding motifs, a paired domain and a homeodomain, and one C-terminal transactivation domain, the proline-serine-threonine rich domain (Osumi et al. 2008; Callaerts et al. 1997). Among these motifs, the so-called paired domain is the characteristic feature of Pax6 which was originally identified in the D. melanogaster segmentation genes paired, gooseberry, and gooseberry neuro (Noll 1993).The paired box (Pax) was found to be conserved across a wide variety of species from metazoans to humans (Burri et al. 1989). In mammals, Pax6 is necessary for specifying the neuroectoderm fate from pluripotent embryonic cells (Zhang et al. 2010), maintaining the neural stem/progenitor cell pool in the mitotically active germinal zone, and producing new neurons from the neural stem/progenitor cells (neurogenesis) (Osumi et al. 2008). It is crucial for forebrain patterning (telencephalic and diencephalic regionalization) in the mouse (Osumi 2001; Manuel and Price 2005; Georgala et al. 2011) and Xenopus (Moreno et al. 2008), and in defining the boundary between adjacent embryonic brain domains. For example, it defines the prosencephalonmesencephalon boundary (Mastick et al. 1997), the pallial-subpallial boundary (Georgala et al. 2011), and rhombomeric boundaries within the hindbrain (Takahashi and Osumi 2011).

Pax6 expression starts as early as embryonic day 8 (E8) in a broad domain in the neuroepithelium in the mouse, at the time when the neural tube is closing. As neurodevelopment proceeds, Pax6 is expressed in the developing brain from the mitotic germinal zone to, later, widely distributed cell groups in the embryonic forebrain, hindbrain (Walther and Gruss 1991; Stoykova and Gruss 1994), midbrain (Stoykova and Gruss 1994), and in the adult brain (Stoykova and Gruss 1994). The expression patterns of Pax6 in distinct regions of the brain throughout neurodevelopment are the basis of the putative Pax6 functions mentioned above. The pattern of Pax6 expression has been extensively studied in the embryonic and adult brain, but some of the data are inconsistent. Several studies have shown that Pax6 is transiently expressed in the ventral mesencephalon in the mouse (Stoykova and Gruss 1994), chick (Schubert and Lumsden 2005) and alligator (Pritz and Ruan 2009), and that it could play a role in promoting the TH-positive neuronal yield of the mouse ventral midbrain in vitro (Spitere et al. 2008), but other reports indicated that Pax6 is not expressed in the mesencephalon at E8 (Walther and Gruss 1991), E12.5 and E14.5 (Georgala et al. 
2011), neither in the substantia nigra (SN) and ventral tegenmental area (VTA) at E12 and E16

(Vitalis et al. 2000). In situ hybridization signals for Pax6 mRNAs were not detectable in the hippocampus in the young adult mouse (Stoykova and Gruss 1994), but one report indicated an intense expression of Pax6 in proliferating precursors of the adult dentate gyrus (Nacher et al. 2005).

To investigate the spatiotemporal expression patterns of Pax6 throughout neurodevelopment from E11 to adult stages, Pax6 expression in the whole brain was analyzed in serial coronal and sagittal sections using immunohistochemistry. Pax6 expression and its colocalization with NeuN and TH in the brain were detected using double immunolabeling. The isotropic fractionator method (Herculano-Houzel and Lent 2005) was used to determine the proportion of cells immunoreative for Pax6 and NeuN in brain homogenates.

\section{Materials and methods}

\section{Animals}

Adult C57/BL6 mice (10-12 weeks old) were obtained from the Animal Resources Centre (ARC), Australia. Mice were housed on 12-h light/dark cycles with free access to food and water. Embryos were obtained by pairing male and female mice. Everyday for 3 days, female mice were exposed to male urine-soaked dirty bedding materials to initiate estrus, and late in the afternoon on the third day the females were paired with males. Early the next morning if a seminal plug was present, the date was designated E0. The care and handling of the adult animals and embryos prior to and during the experimental procedures was approved by the Animal Care and Ethics Committee of the University of New South Wales Australia (approval number 08/48B, 11/75A).

\section{Tissue preparation}

Preparation of the adult mouse brain tissues followed the procedures described by Liang et al (2010). Adult mice were anesthetized with a lethal dose of sodium pentobarbitone $(0.1 \mathrm{ml}, 200$ $\mathrm{mg} / \mathrm{ml}$ ) and perfused through the left ventricle, first with $60 \mathrm{ml}$ of $0.9 \%$ normal saline to flush the blood vessels quickly, followed by $80 \mathrm{ml}$ of cold $4 \%$ paraformaldehyde (PFA, Sigma) in $0.1 \mathrm{M}$ phosphate buffer (PB, $\mathrm{pH}$ 7.4). The brains were removed from the skull, postfixed in 4\% PFA for 
$6 \mathrm{~h}$ at room temperature, followed by cryoprotection in $30 \%$ sucrose in $0.1 \mathrm{M} \mathrm{PB}(\mathrm{pH} 7.4)$

overnight at $4{ }^{\circ} \mathrm{C}$.

The embryonic brain tissues were prepared in accordance with Vitalis et al (2000). Embryos at stages from E11 to E17 were used in the present experiment. Embryos of E11, E12 and E13 were dissected from deeply anesthetized mothers and immersion fixed in 4\% PFA in $0.1 \mathrm{M} \mathrm{PB}$ for 5 days. Embryos from E14 to E17 and postnatal mice were firstly anesthetized and then perfused transcardially with normal saline, followed by $4 \%$ PFA in $0.1 \mathrm{M}$ PB for 2 min. The brains were postfixed in $4 \%$ PFA and cryoprotected in $30 \%$ sucrose in $0.1 \mathrm{M} \mathrm{PB}$.

Serial sagittal or coronal sections of the whole brain were cut at $40 \mu \mathrm{m}$ thickness on a cryotome (Leica CM 1950). Sections were mounted onto gelatinized slides and dried at room temperature overnight. The mounted sections were processed for immunocytochemistry or kept at $-40{ }^{\circ} \mathrm{C}$ for long-term storage.

\section{Immunohistochemistry}

Sections were treated with $10 \mathrm{mM}$ citrate buffer $(\mathrm{pH} 6.0)$ at $95^{\circ} \mathrm{C}$ for $15 \mathrm{~min}$ for antigen retrieval, the endogenous peroxidase was quenched by $1 \%$ hydrogen peroxide in $50 \%$ ethanol for $30 \mathrm{~min}$ at room temperature. After washes in PBS, the sections were blocked for $3 \mathrm{~h}$ at room temperature in a blocking solution (Vitalis et al. 2000) containing $2 \%$ bovine serum albumin, $2 \%$ goat serum, $7 \%$ glycerol, and $0.2 \%$ Tween $20(\mathrm{BS})$, followed by incubation at $4{ }^{\circ} \mathrm{C}$ for $72 \mathrm{~h}$ with a rabbit polyclonal antibody against Pax6 (Chemicon, 1:600 dilution, $1.67 \mu \mathrm{g} / \mathrm{ml}$ ). Control was achieved by substituting normal rabbit serum for Pax6 antibody at the same concentration $(1.67 \mu \mathrm{g} / \mathrm{ml})$. Sections were firstly incubated with goat anti-rabbit biotinylated antibody (Sigma, 1:200 dilution), and then exposed to ExtrAvidin peroxidase (Sigma, 1:1000 dilution), at room temperature for $2 \mathrm{~h}$. The primary-secondary antibody conjugates were visualized by treatment for $2-5 \mathrm{~min}$ in $0.05 \mathrm{M}$ Tris buffer ( $\mathrm{pH} 7.5$ ) containing $0.05 \%$ 3,3'-diaminobenzidine tetrahydrochloride (DAB, Sigma), $0.3 \%$ nickel ammonium sulfate, and $0.03 \%$ hydrogen peroxide. The color reaction was stopped with several washes of PBS. The sections were dehydrated with a graded ethanol series, cleared with xylene, and coversliped with DPX (Sigma).

\section{Double immunolabeling}


Sections were hydrated in PBS, quenched in $1 \%$ hydrogen peroxide, and blocked in the blocking solution as mentioned above. Sections were then incubated at $4{ }^{\circ} \mathrm{C}$ for $72 \mathrm{~h}$ with a mixture of a rabbit anti-Pax6 antibody (Chemicon, 1:600 dilution) and a mouse anti-TH antibody (Sigma, 1:1600 dilution), or with a mixture of a rabbit anti-Pax6 antibody and a mouse anti-NeuN antibody (Sigma, 1:1600). The sections were incubated at room temperature for $2 \mathrm{~h}$ with secondary antibodies: a FITC anti-mouse antibody (Chemicon, 1:200 dilution) and a goat anti-rabbit biotinylated antibody (Sigma, 1:200 dilution). Sections were then exposed to the ExtrAvidin peroxidase (Sigma, 1:1000 dilution) at room temperature for $2 \mathrm{~h}$. Sections were coverslipped with fluorescent mounting medium (Dako) and the fluorochrome FITC labeled antibody was visualized and photographed under a fluorescent microscope (Olympus BX51) equipped with a Carl Zeiss camera (AxioCam HRc). After removal of the coverslip, the biotinylated antibody was finally visualized by using the above protocol. The sections were dehydrated, re-coversliped and scanned with Aperio Digital Pathology Systems (ScanScope XT). Photographs of DAB stained sections were treated with a computer program (Adobe Photoshop) to change the tone of the pictures and merged with corresponding fluorescence images (Yamada et al. 2005).

Pax6, TH, and NeuN-labeled cells in the coronal and sagittal sections were mapped and analyzed with reference to the atlases of the developing and adult mouse brain (Franklin and Paxinos 2008 ; Paxinos et al. 2007), the atlas of the developing rat nervous system (Ashwell and Paxinos 2008), and the reports on Pax6 expression (Walther and Gruss 1991; Stoykova and Gruss 1994). The nomenclature and abbreviations for neuronal groups are taken from Ashwell and Paxinos (2008) and Allen Brain Atlas Resources [Internet], Seattle (WA): Allen Institute for Brain Science (data available from: http://www.brain-map.org).

\section{Isotropic fractionator}

The total number of nuclei and the proportion of Pax6 and/or NeuN positive cells in each sample were determined using the isotropic fractionator method (Herculano-Houzel and Lent 2005). After at least $14 \mathrm{~d}$ postfixation, the adult mouse brain was dissected into five regions: olfactory bulb, cortex, cerebellum, hippocampus, and remaining areas. The dissected regions were cut into thin slices to prepare suspensions of intact cell nuclei through mechanical dissociation in a dissociation solution (1\% Triton X-100 in $40 \mathrm{mM}$ sodium citrate), using Tenbroeck tissue grinder (glass 
homogenizer). The homogenates and the washes were collected for centrifuging at $4000 \times \mathrm{g}$ for 10 min. The supernatant was discarded carefully and the pelleted nuclei were suspended in PBS by gentle pipetting.

The proportion of Pax6-positive neurons was estimated by immunostaining of Pax6 and NeuN from a $500 \mu \mathrm{l}$ aliquot of the nucleus suspension. The suspension was centrifugated, the supernatant removed, and the pellent resuspended in $0.2 \mathrm{M}$ boric acid solution ( $\mathrm{pH}$ 9.0) for antigen retrieval at $75^{\circ} \mathrm{C}$ for $1 \mathrm{~h}$. The nuclei were again collected by centrifugation, washed in PBS, and incubated overnight at room temperature with an anti-NeuN mouse antibody (Sigma, 1:500 dilution) and an anti-Pax6 rabbit antibody (Chemicon,1:300 dilution) in 10\% goat serum. After washing three times in PBS, the suspension was incubated with FITC-conjugated goat anti-mouse antibody (Chemicon, 1:300 dilution) and Alexa Fluor 594 labeled goat anti-rabbit antibody (Invitrogen, 1:300 dilution) in 10\% goat serum and 50\% DAPI (4',6-diamidino-2-phenylindole, dilactate) (10 mg/l, Molecular Probes) at room temperature for $2 \mathrm{~h}$. The cell nuclei were collected by centrifugation, washed 3 times in PBS, and suspended in PBS. After sufficient agitation, a 10 $\mu \mathrm{l}$ aliquot was taken to detect DAPI-stained nuclei, FITC labeled NeuN positive nuclei, and Alexa Fluor 594 labeled Pax6 positive nuclei using a hemocytometer through fluorescence microscopy at $400 \times$ magnification. At least 500 DAPI-stained Nuclei were counted and the percentages of NeuN and/or Pax6 positive nuclei were determined from the DAPI bright blue-fluorescing nuclei. The remaining nuclei can be collected for long-term storage (Herculano-Houzel and Lent 2005). The suspension was spun down in a centrifuge, the supernatant discarded, and the pellents resuspend in $30 \%$ sucrose in PBS for equilibration overnight at $4{ }^{\circ} \mathrm{C}$. The nuclei were spun down again and resuspended in an antifreeze solution (30\% glycerol and 30\% ethylene glycol in $24 \mathrm{mM}$ phosphate buffer) to equilibrate overnight at $4{ }^{\circ} \mathrm{C}$, and then stored at $-20{ }^{\circ} \mathrm{C}$ until the next use.

\section{Results}

\section{Spatial distribution of Pax6 in the embryonic brains}

In the sagittal sections of the embryonic brains, Pax6 expression was detected in the forebrain (telencephalon and diencephalon), midbrain (mesencephalon) and hindbrain (isthmus and rhombencephalon). In the telencephalon, Pax6 immunopositive cells were found in the nearly entire layer of the primordial cortex at E11 to E13 (Fig. 1A1, B1, C1), and in the ventricular zone 
(VZ) of the cortex at E14 onward (Fig. 1D1, E1 and F1). In the diencephalon, it is prominently expressed in the pretectum (Fig. 1A2, B2, C2, D2, E', F2) and prethalamus (Fig. 1A3, B3, C3, D3, $\mathrm{E} 2, \mathrm{~F} 3)$, forming sharp boundaries with the mesencephalon at the posterior commissure (pc) and with the thalamus at the sulcus diencephalicus medius, respectively. In the midbrain, Pax6 is mainly expressed in the mesencephalic reticular formation (mRt) (Fig. 1A4, B4, C4, D4, E3, F4). In the hindbrain, it is expressed in the ventricular zone (VZ) of the fourth ventricle (Fig. 1A5, B5, C5, D5, E4, F'), and in the external granular layer (EGL) of the developing cerebellum (Fig. 1D5, E4, F').
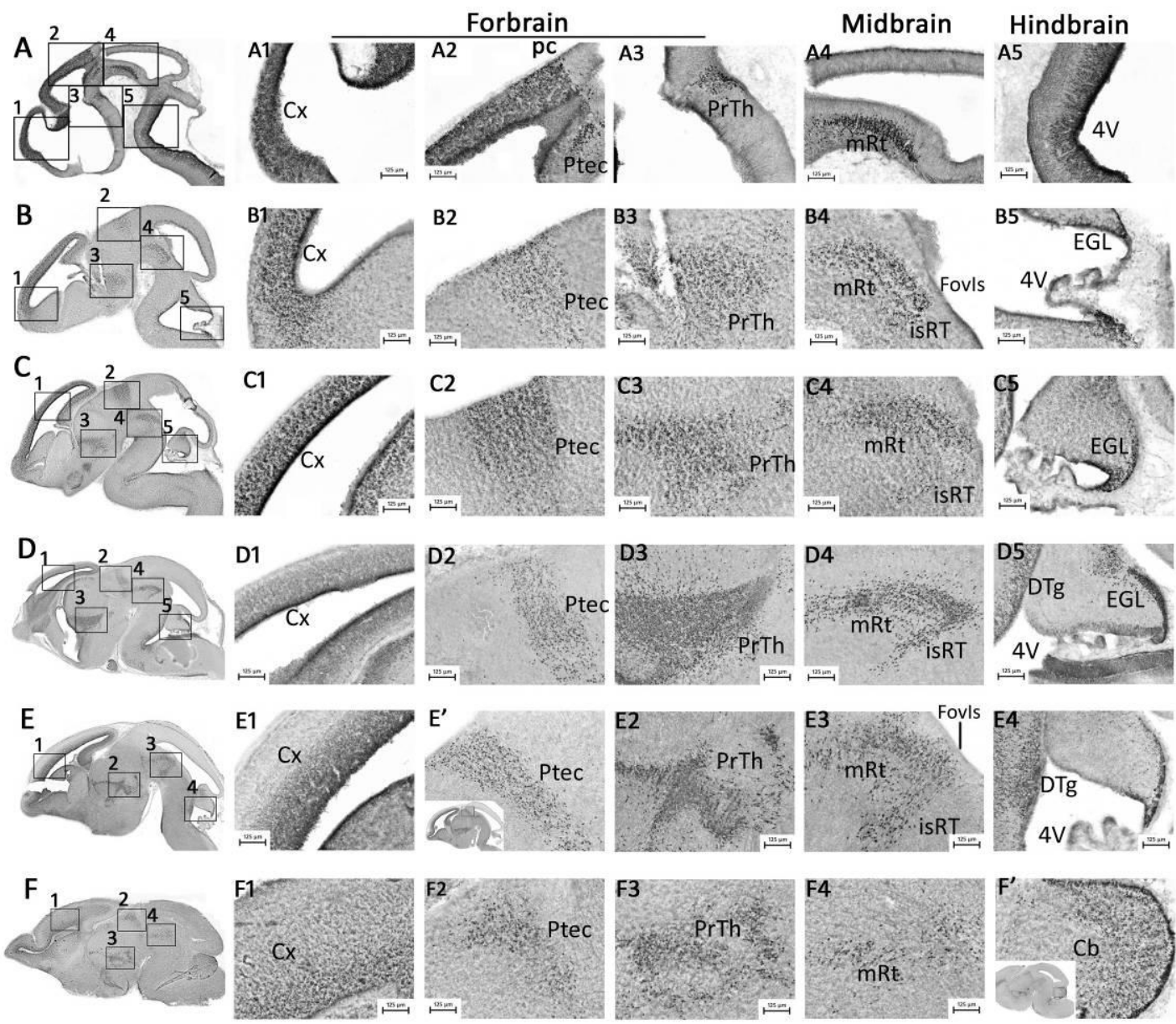

G
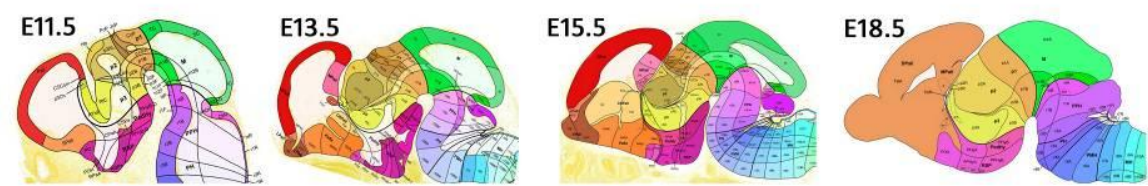

Fig.1 Pax6 immunoreactivity in the embryonic brains viewed sagittally. The top six rows represent the Pax6-immunostaining sections at E11(A), E12(B), E13(C), E14(D), E15(E) and E17(F), respectively. The photomicrographs of the five right-hand columns are separately taken from the corresponding numbered boxed areas of the first left column and they illustrate at higher 
magnification the Pax6 positive areas in the forebrain, midbrain and hindbrain. The bottom row $(\mathrm{G})$ shows embryonic brain atlases from Allen Brain Atlas Resources [Internet] (data available from: http://www.brain-map.org).

\section{Temporal distribution of Pax6 in the embryonic, neonate, and adult brains}

At E11, Pax6 expression was widely distributed in the ventricular zone (VZ) in the forebrain and hindbrain, but not in VZ in the midbrain (Fig. 2A-E). In the forebrain (telencephalon and diencephalon), Pax6 was expressed in nearly the whole layer of the ventricular zone in the telencephalon (Fig. 2A-C, inset in Fig. 2G), and in the pretectum (Fig. 2B - E, inset in Fig. 2G) and prethalamus (Fig. 2A-B, 2H) in the diencephalon. A higher level of Pax6 expression was observed in the rostral-lateral cerebral cortex (Fig. 2G) than in the caudal-medial cortex (Fig. 2H). In the midbrain (mesencephalon), Pax6 was expressed in the mesencephalic reticular formation (mRt) (arrow in Fig. 2C, inset in Fig. 2H) and the floor of the mesencephalon (arrowhead in Fig. 2E'). In the hindbrain (rhombencephalon), it is mainly expressed in the ventricular zone (Fig. 2AC, inset in Fig. 2K). 

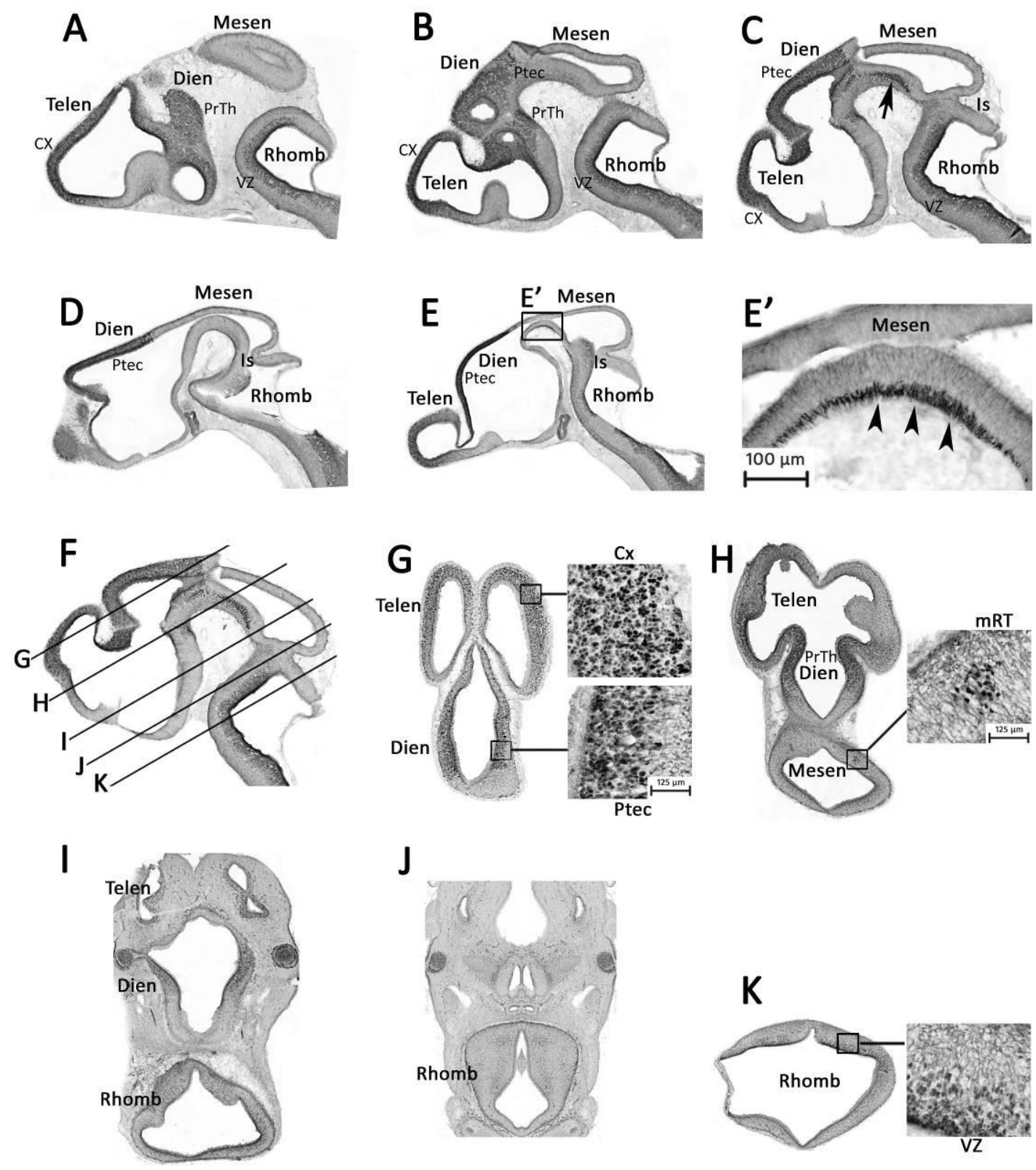

Fig. 2 Pax6 expression in an E11 brain viewed sagittally and horizontally. Pax6 expression in the telencephalon, diencephalon and rhombencephalon is shown in sagittal sections from lateral (A) to medial plate $(E)$, and in horizontal sections from anterior $(G)$ to posterior plane $(K)$. Insets in $G$ show the cortex and pretectum in the prosencephalon at higher magnification. In the mesencephalon, the positive cells were observed in the $\mathrm{mRt}$ (arrow in $\mathrm{C}$ and inset in $\mathrm{H}$ ) and the floor (arrowhead in E'). The inset in K shows the ventricular zone in the rhombencephalon at higher magnification. Panel F indicates a schematic representation of the levels of the sections in G-K. 
From E12 onward, expression of Pax6 was observed not only in the neuroepithelia of the ventricular zone but also in the extensively distributed cell groups as neurodevelopment proceeds. The overall distribution of Pax6 in the cell groups of the embryonic, neonate, and adult brain was shown in Fig.3 (E12), Fig. 4 (E13, E14), Fig. 5 and Fig. 6 (E15, E17 and P1), and Fig. 7 (adult) and summarized in Table 1.

In the secondary prosencephalon, Pax6 is expressed in nearly the whole layer of dorsolateral prosencephalic neuroepithelium from E11 until E13. After E15, it is confined to the ventricular zone and is maintained in the subventricular zone of the adult mouse cortex. Pax6 cells were seen in the septum (medial septal nucleus and the lateral septal nucleus, intermediate part), piriform cortex, anterior olfactory nucleus, amygdaloid area, preoptic area (lateral preoptic area), ventral pallidum, globus pallidus, prethalamic eminence, and hippocampus (dentate gyrus) at E12; in the diagonal domain (nucleus of the horizontal limb of the diagonal band, nucleus of the vertical limb of the diagonal band), several cell groups of the amygdaloid area (anterior amygdaloid area, intercalated nuclei of the amygdala, and the central, medial, basolateral and basomedial amygdaloid nuclei), entopeduncular nucleus, olfactory tubercle at E13; in the taenia tecta (ventral and dorsal tenia tecta), glomerular layer of the olfactory bulb, and lateral hypothalamus (peduncular part of the lateral hypothalamus, juxtaparaventricular part of the lateral hypothalamus) at E15.

In the diencephalon, Pax6 is strongly expressed in the pretectum, thalamus (lateral habenular nucleus and medial habenular nucleus), and prethalamus (pregeniculate nucleus, subgeniculate nucleus, zona incerta, and reticular thalamic nucleus) at E12. At later stages in development, Pax6 expression is detected in many differentiating structures - the anterior pretectal nucleus, lateral nuclei (lateral posterior thalamic nucleus and laterodorsal thalamic nucleus), and subparafascicular thalamic nucleus, parvicellular part, at E13; the magnocellular nucleus of the posterior commissure, the nucleus of the posterior commissure, precommissural nucleus, and the nucleus of the field of Forel at E15.

Pax6 expression in regions of the embryonic forebrain brains was mostly maintained in these same regions in the adult brain, except for the dentate gyrus, globus pallidus, and lateral thalamic nuclei (lateral posterior thalamic nucleus and laterodorsal thalamic nucleus). In the mesencephalon, Pax6 expression was observed in the mesencephalic reticular formation at 
E12, in the interstitial nucleus of Cajal and periaqueductal gray at E13, and persisted in all of these cell groups in the adult midbrain.

In the rhombencephalon, Pax6 was expressed in the nucleus of the lateral lemniscus, external granular layer of the developing cerebellum, superior and medial vestibular nucleus, and gigantocellular reticular nucleus at E12; in the pontine nuclei, dorsal raphe nucleus, central gray, isthmic reticular formation, reticulotegmental nucleus of the pons, ventral and dorsal cochlear nucleus, inferior olivary nucleus, and medioventral periolivary nucleus at E13; in the lateral reticular nucleus, external cuneate nucleus, nucleus X, median raphe nucleus, laterodorsal and posterodorsal tegmental nuclei, motor trigeminal nucleus (parvicellular part), and linear nucleus at E15. In the adult hindbrain, no obvious expression of Pax6 was observed in the median raphe nucleus, lateral reticular nucleus, external cuneate nucleus, motor trigeminal nucleus (parvicellular part), inferior olivary nucleus, medioventral periolivary nucleus, and gigantocellular reticular nucleus. 

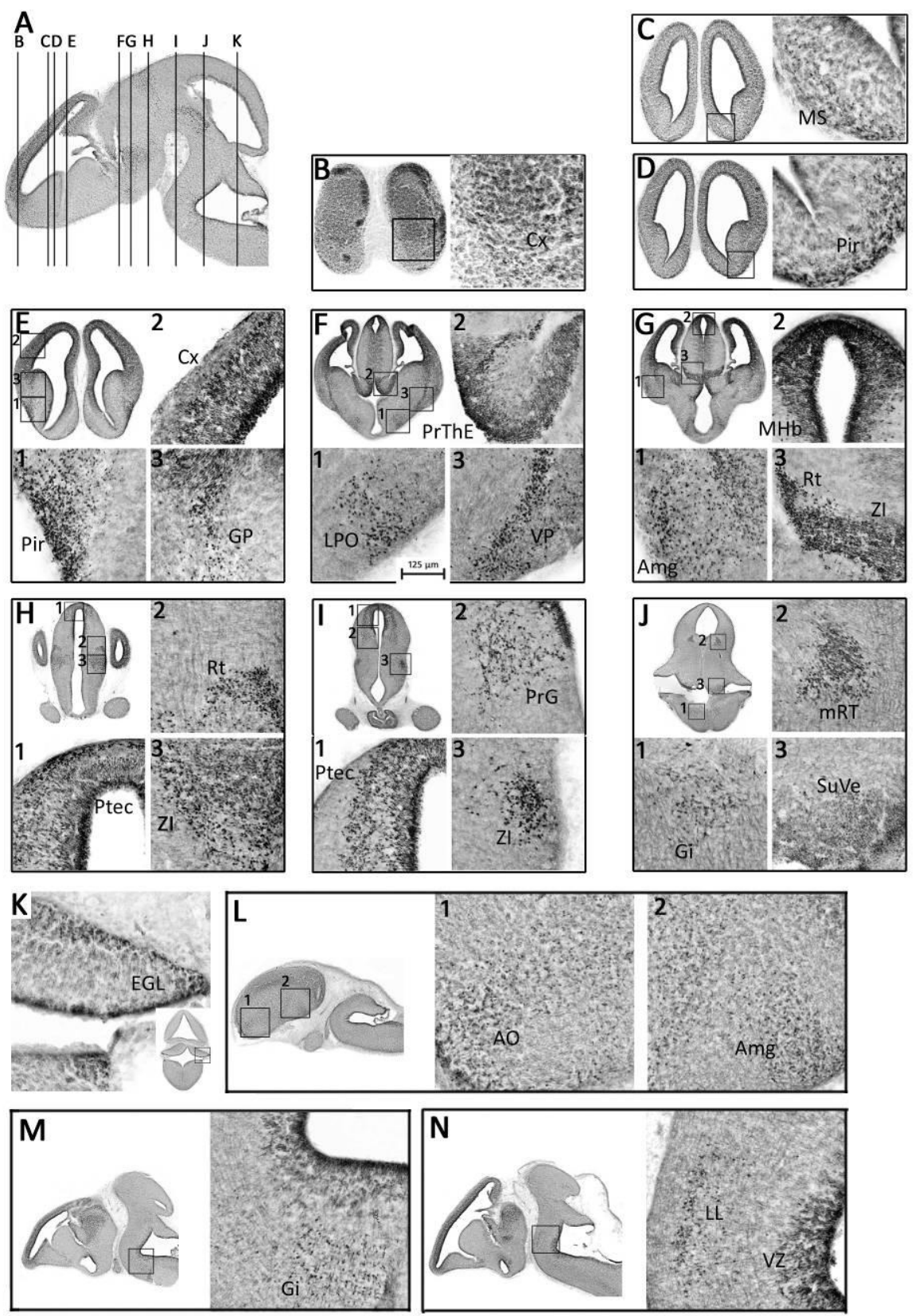

Fig. 3 Expression of Pax6 in the E12 brain. Pax6 immunoreactivity is illustrated in the

neuroepithelium of the ventricular zone and cell groups in the forebrain, midbrain and hindbrain viewed coronally (B-K) and sagittally (L-N). Panel A indicates a schematic representation of the levels of the coronal sections in B-K. 

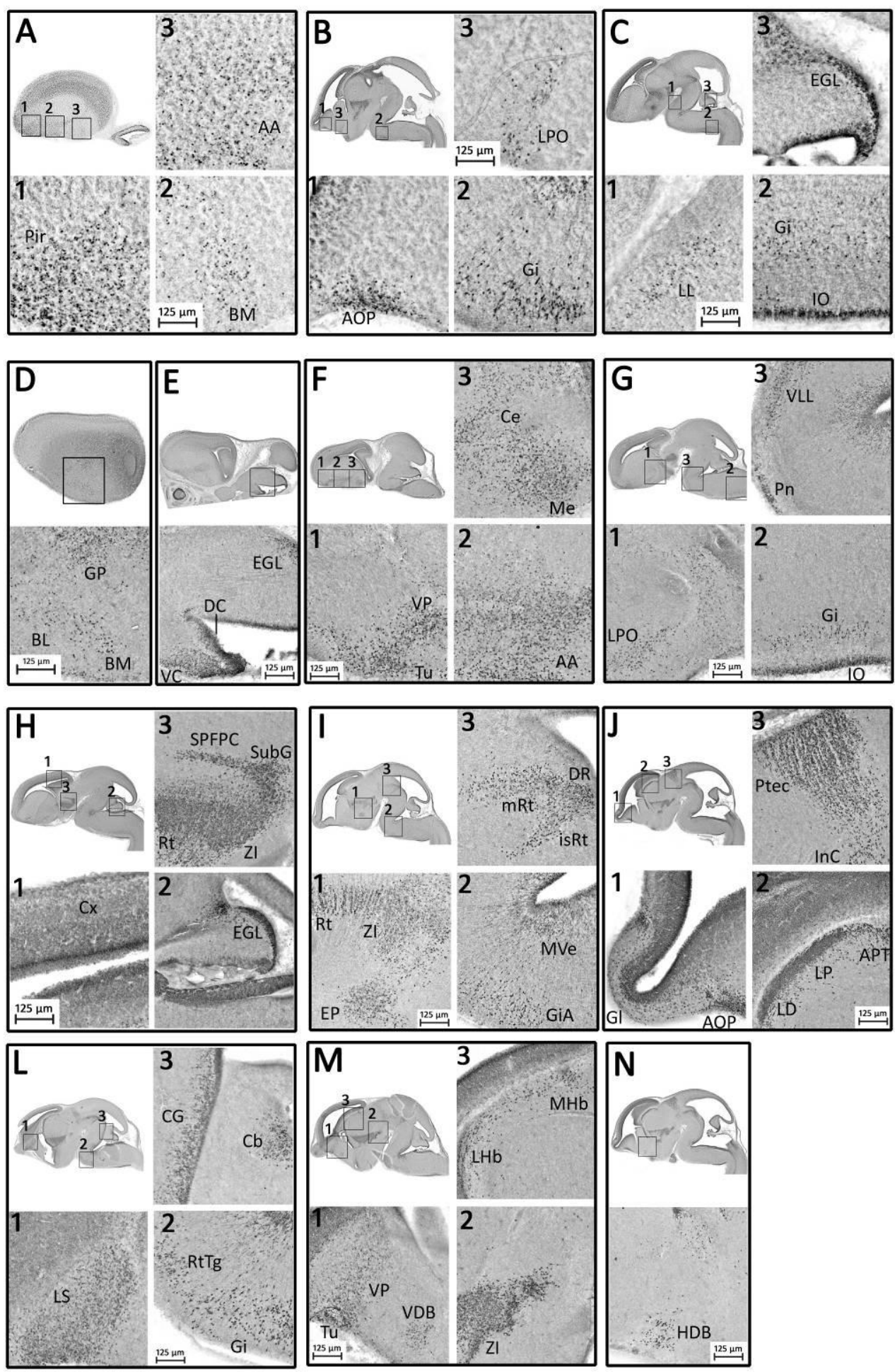

Fig. 4 Pax6 expression in sagittal sections of the E13 (A-C) and E14 (D-N) brains. 


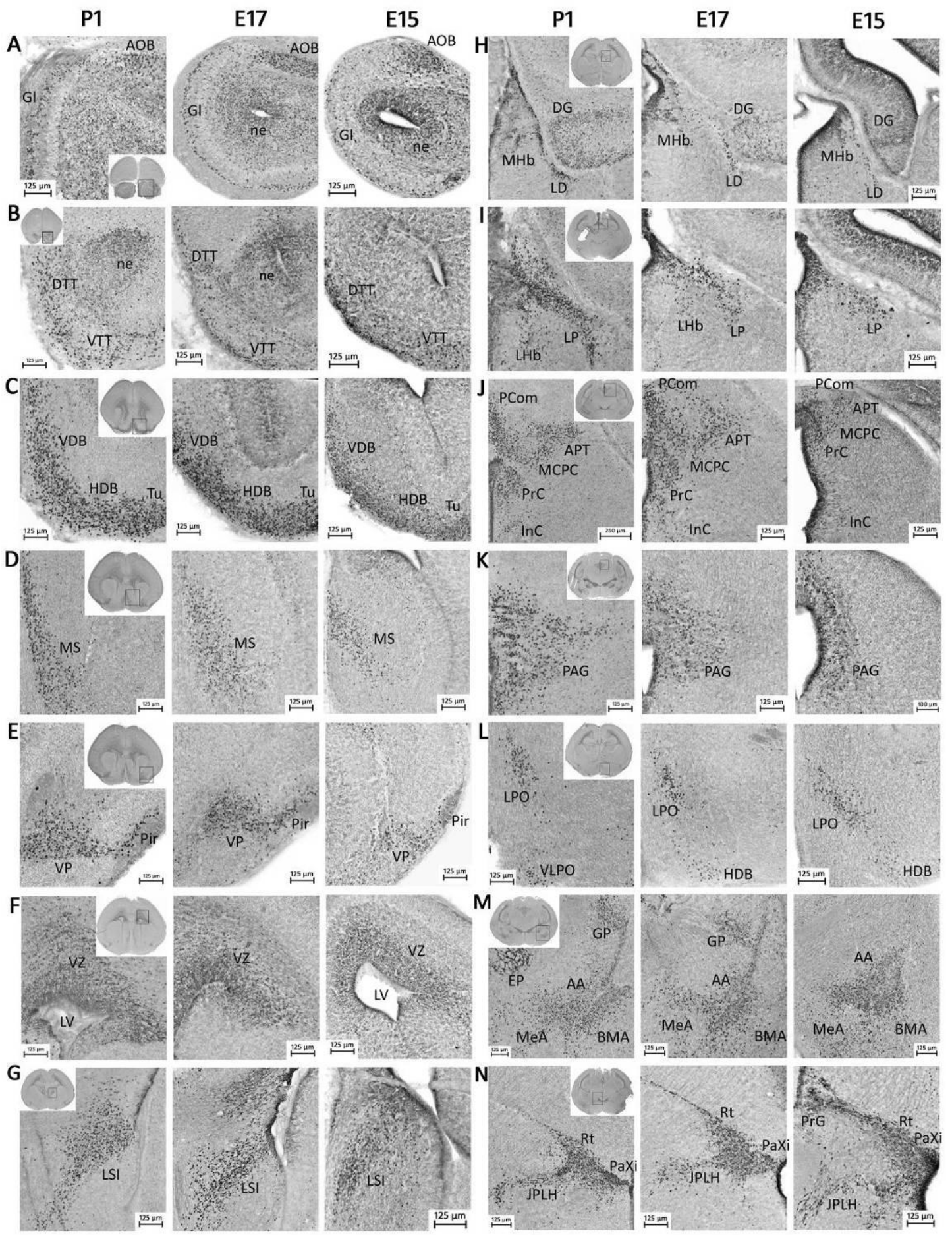

Fig. 5 Expression of Pax6 in coronal sections of the E15, E17, and P1 mouse prosencephalon 


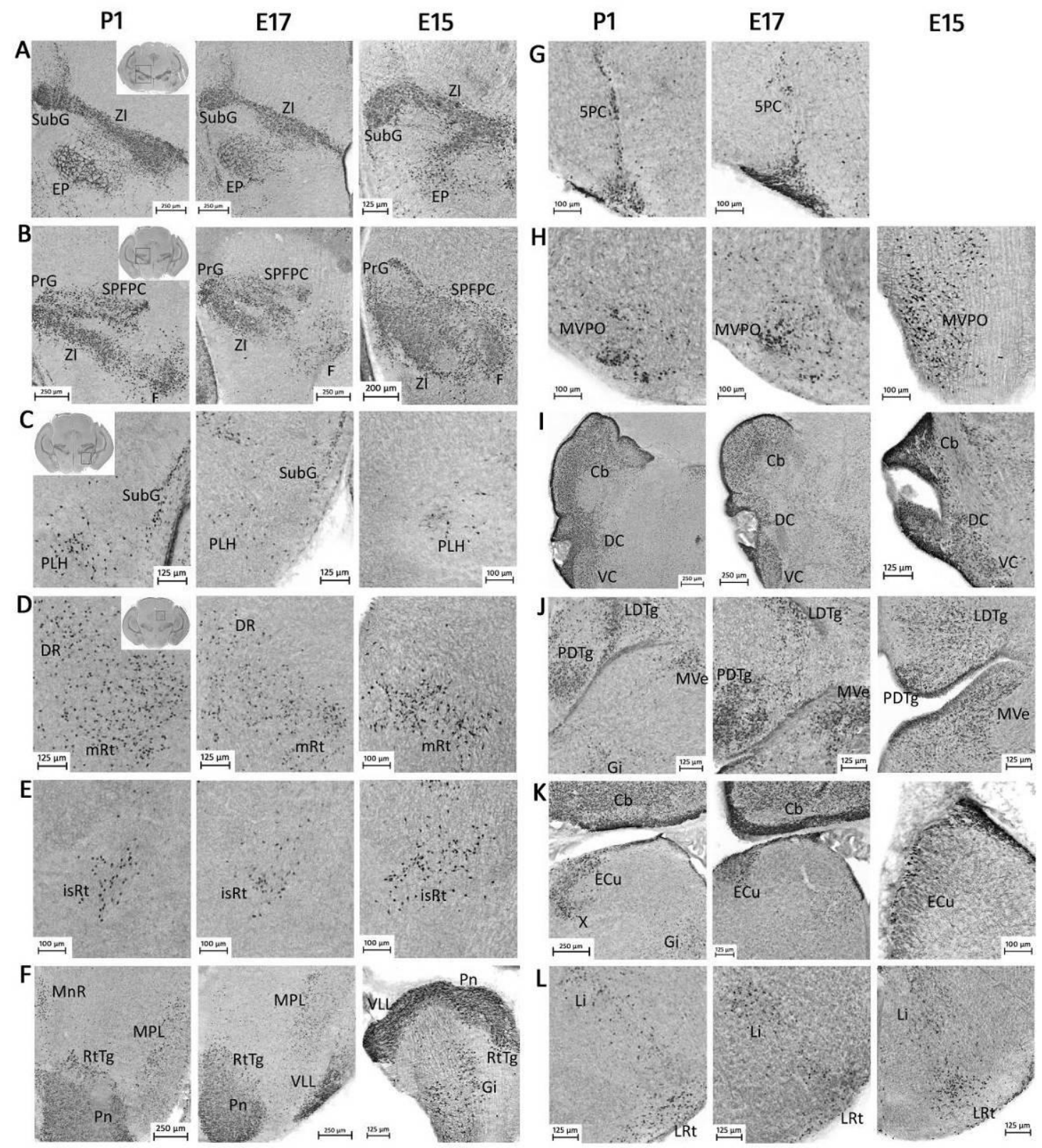

Fig. 6 Expression of Pax6 in coronal sections of the diencephalon, mesencephalon and rhombencephalon at E15, E17, and P1 


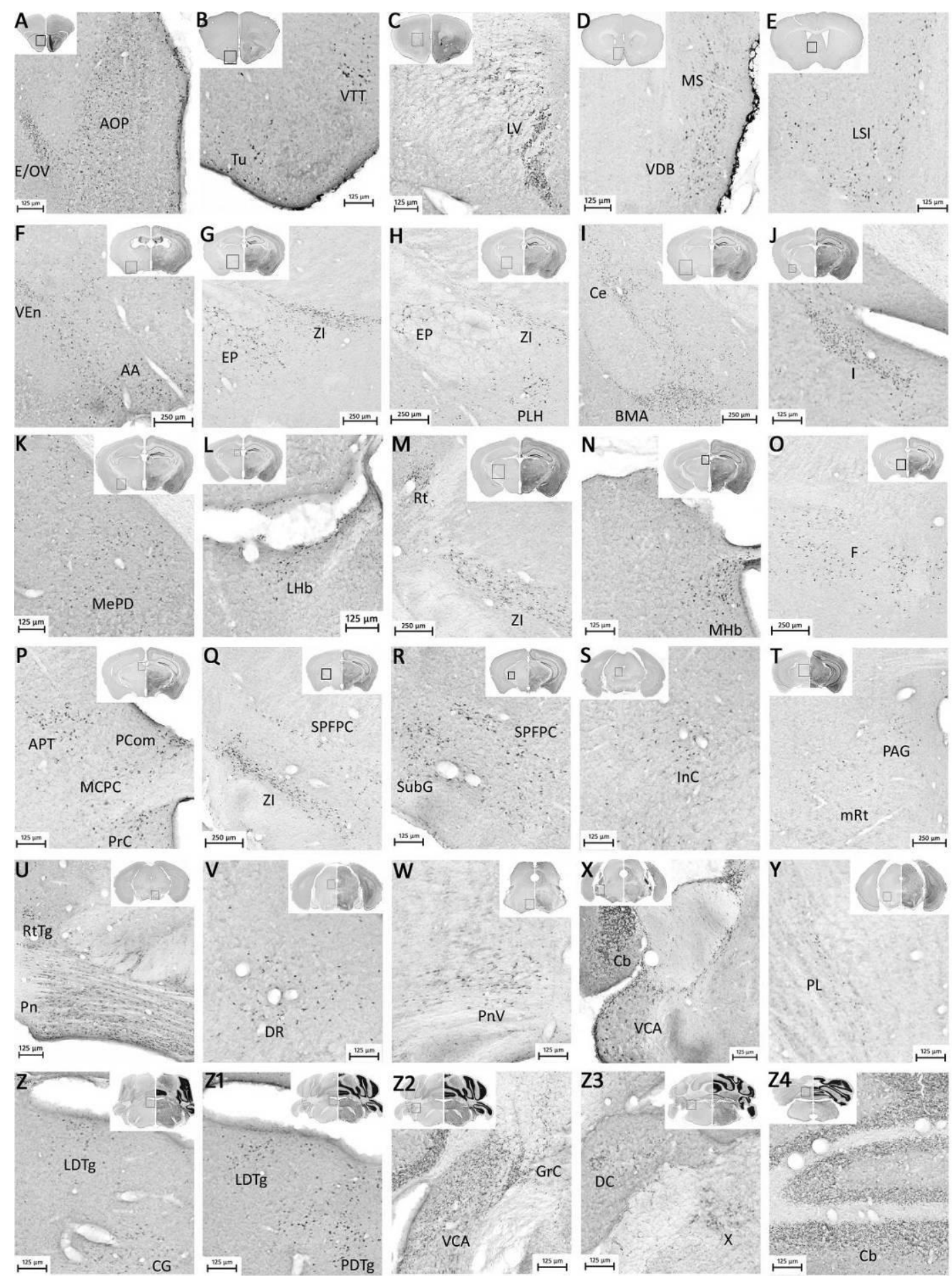

Fig. 7 Expression of Pax6 in coronal sections of adult mouse brain

Table 1 Pax6 expression in the embryonic, neonate, and adult mouse brain

\begin{tabular}{|c|c|c|c|c|}
\hline $\begin{array}{l}\text { Pax6 Cell } \\
\text { groups }\end{array}$ & E12 & E13, E14 & $\begin{array}{l}\text { E15, E17, and } \\
\text { P1 }\end{array}$ & Adult \\
\hline \multicolumn{5}{|c|}{ Secondary Prosencephalon } \\
\hline $\mathrm{Gl}$ & & & Fig. 5A & Not shown \\
\hline $\mathrm{AO}$ & Fig. 3L1 & Fig. 4B1, 4J1 & Fig. $5 \mathrm{~A}$ & Fig. 7A \\
\hline VTT/DTT & & & Fig. 5B & Fig. 7B \\
\hline
\end{tabular}




\begin{tabular}{|c|c|c|c|c|}
\hline \multicolumn{2}{|l|}{ VDB/HDB } & Fig. 4M1, 4N & Fig. 5C, 5L & Fig. 7D \\
\hline $\mathrm{Tu}$ & & Fig. 4M1, 4F1 & Fig. 5C & Fig. 7B \\
\hline MS/LSI & Fig. 3C & Fig. 4L1 & Fig. 5D, 5G & Fig. 7D, 7E \\
\hline Pir & Fig. 3D, 3E1 & Fig. 4 A1 & Fig. 5E & not shown \\
\hline VP & Fig. 3F3 & Fig. 4F1, 4M1 & Fig. 5E & not shown \\
\hline DG & & & Fig. $5 \mathrm{H}$ & \\
\hline GP & Fig. 3E3 & Fig. 4D & Fig. 5M & \\
\hline LPO & Fig. 3F1 & Fig. 4B3, 4G1 & Fig. 5L & not shown \\
\hline AA & Fig. 3G1, 3L2 & Fig. 4A3, 4F2 & Fig. 5M & Fig. 7F \\
\hline $\mathrm{BM} / \mathrm{BL}$ & & Fig. 4A2, 4D & Fig. 5M & Fig. 7I \\
\hline $\mathrm{Me}$ & & Fig. 4F3 & Fig. 5M & Fig. 7K \\
\hline I & & & data not shown & Fig. 7J \\
\hline $\mathrm{Ce}$ & & Fig. 4F3 & data not shown & Fig. 7I \\
\hline JPLH & & & Fig. $5 \mathrm{~N}$ & not shown \\
\hline PLH & & & Fig. 6C & Fig. 7H \\
\hline EP & & Fig. 4I1 & Fig. 6A & Fig. 7G, H \\
\hline \multicolumn{5}{|c|}{ Diencephalon } \\
\hline Pretectum & Fig. 3H1, 3I1 & Fig. 4J3 & & \\
\hline МCPC & & & Fig. 5J & Fig. 7P \\
\hline PCom & & & Fig. 5J & Fig. 7P \\
\hline $\operatorname{PrC}$ & & & Fig. $5 \mathrm{~J}$ & Fig. 7P \\
\hline APT & & Fig. $4 \mathrm{~J} 2$ & Fig. $5 \mathrm{~J}$ & Fig. 7P \\
\hline \multicolumn{5}{|l|}{ Thalamus } \\
\hline MHb, LHb & Fig. 3G2 & Fig.4M3 & Fig. 5H, 5I & Fig. 7L, 7N \\
\hline LP, LD & & Fig. 4J2 & Fig. 5H, 5I & \\
\hline SPFPC & & Fig. 4H3 & Fig. 6B & Fig. 7Q, 7R \\
\hline \multicolumn{5}{|l|}{ Prethalamus } \\
\hline SubG, PrG & Fig. 3I2 & Fig. 4H3 & $\begin{array}{l}\text { Fig. 6A, 6B, } \\
6 \mathrm{C}\end{array}$ & Fig. 7R \\
\hline Rt & Fig. 3G3, H2 & Fig. 4H3, 4I1 & Fig. $5 \mathrm{~N}$ & Fig. 7M \\
\hline ZI & $\begin{array}{l}\text { Fig. 3G3, H3, } \\
\text { I3 }\end{array}$ & $\begin{array}{l}\text { Fig. } 4 \mathrm{H} 3,4 \mathrm{H} 1 \text {, } \\
4 \mathrm{M} 2\end{array}$ & Fig. 6A, 6B & $\begin{array}{l}\text { Fig. 7G, 7H, } \\
\text { 7M, 7Q }\end{array}$ \\
\hline $\mathrm{F}$ & & & Fig. 6B & Fig. 70 \\
\hline \multicolumn{5}{|c|}{ Mesencephaon } \\
\hline PAG & & & Fig. 5K & Fig. 7T \\
\hline $\mathrm{mRt}$ & Fig. $3 \mathrm{~J} 2$ & Fig. 4I3 & Fig. 6D & Fig. $7 \mathrm{~T}$ \\
\hline InC & & Fig. $4 \mathrm{~J} 3$ & Fig. 5J & Fig. 7S \\
\hline \multicolumn{5}{|c|}{ Is and Rhombencephalon } \\
\hline isRt & & Fig. 4I3 & Fig. 6E & \\
\hline LDTg/PDTg & & & Fig. $6 \mathrm{~J}$ & Fig. $7 \mathrm{Z}, 7 \mathrm{Z1}$ \\
\hline LL, PL & Fig. 3N & Fig. 4C1, 4G3 & Fig. $6 \mathrm{~F}$ & Fig. 7Y \\
\hline DR & & Fig. 4I3 & Fig. 6D & Fig. 7V \\
\hline EGL, Cb & Fig. 3K & $\begin{array}{l}\text { Fig. } 4 \mathrm{C} 3,4 \mathrm{E}, \\
4 \mathrm{H} 2,4 \mathrm{~L} 3\end{array}$ & Fig. 6I, 6K & Fig. $7 \mathrm{X}, 7 \mathrm{Z4}$ \\
\hline CG & & Fig. 4L3 & & Fig. 7Z \\
\hline Pn & & Fig. 4G3 & Fig. $6 \mathrm{~F}$ & Fig. 7U, 7W \\
\hline MnR & & & Fig. $6 \mathrm{~F}$ & \\
\hline$X$ & & & Fig. 6K & Fig. 7Z3 \\
\hline LRt & & & Fig. 6K & \\
\hline $\mathrm{ECu}$ & & & Fig. $6 \mathrm{~K}$ & \\
\hline RtTg & & Fig. 4L2 & Fig. $6 \mathrm{~F}$ & Fig. 7U \\
\hline SuVe, MVe & Fig. 3J3 & Fig. 4I2 & Fig. $6 \mathrm{~J}$ & Fig. $7 \mathrm{Z1}$ \\
\hline $\mathrm{VC}, \mathrm{DC}$ & & Fig. 4E & Fig. 6I & $\begin{array}{l}\text { Fig. 7X, } \\
\text { 7Z2,7Z3 }\end{array}$ \\
\hline $5 \mathrm{PC}$ & & & Fig. $6 \mathrm{G}$ & \\
\hline IO/MVPO & & Fig. 4C2, 4G2 & Fig. $6 \mathrm{H}$ & \\
\hline $\mathrm{Gi}$ & Fig. 3J1, 3M & Fig. 4B2, 4C2, & Fig. 6F, 6J, 6L & \\
\hline
\end{tabular}




\section{Double immunolabeling of Pax6 and NeuN in the brain}

Double immunolabeling of Pax6 and NeuN with DAB and fluorescent dye FITC was performed in coronal sections of embryonic brains. The black-blue color of DAB was artificially changed to red using Adobe Photoshop. At E11, the telencephalic neuroepithelium consists entirely of Pax6 positive cells, at a time when no obvious NeuN expression was observed in the telencephalon (Fig. 8A). At E15, more NeuN positive cells were observed in the cerebral cortex (Fig. 8B), amygdaloid area (Fig. 8C), and juxtaparaventricular part of lateral hypothalamus (Fig. 8D). Within all of these locations, no obvious Pax6 protein was observed to co-localize with NeuN.
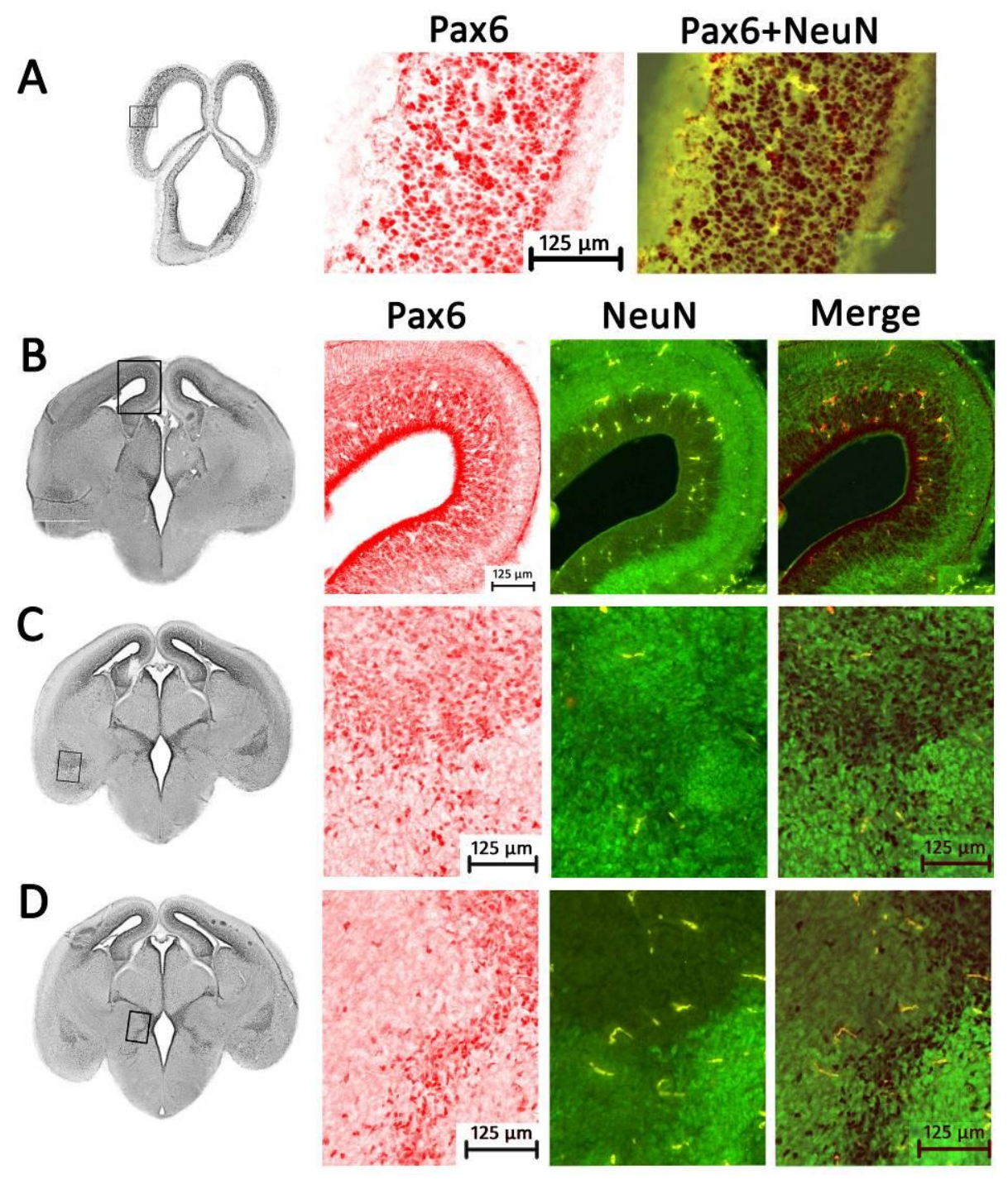

Fig. 8 Double immunolabeling of Pax6 and NeuN in the embryonic brains. At E11, the telencephalic neuroepithelium consists entirely of Pax6 positive cells but without NueN 
expression (A). At E15, NeuN positive cells were observed in coronal sections of the cerebral cortex (B), amygdaloid areas (C) and juxtaparaventricular part of lateral hypothalamus (D), but there was no obvious co-localization of Pax6 cells with NeuN.

\section{Double immunolabeling of Pax6 and TH}

Double immunolabeling of Pax6 and TH with DAB and the fluorescent dye FITC was performed in sagittal sections of the E11, E12, and E14 brains, and in coronal sections of the postnatal brain. The black-blue color of DAB was artificially changed to red using Adobe Photoshop. Pax6 expression was detected in the TH-positive floor of the mesencephalon at E11, but these two proteins were not found to be co-localized in the same cell (Fig. 9A). Pax6 expression was not observed in the TH-positive substantia nigra (SN) and ventral tegmental area (VTA) at E12 (Fig. 9B), P1 (Fig. 9C), and E14 (SN in Fig. 9E, VTA in Fig. 9F). Pax6 is not expressed in the THpositive locus coeruleus (LC) of the rhombencephalon at P1 (Fig. 9D). 

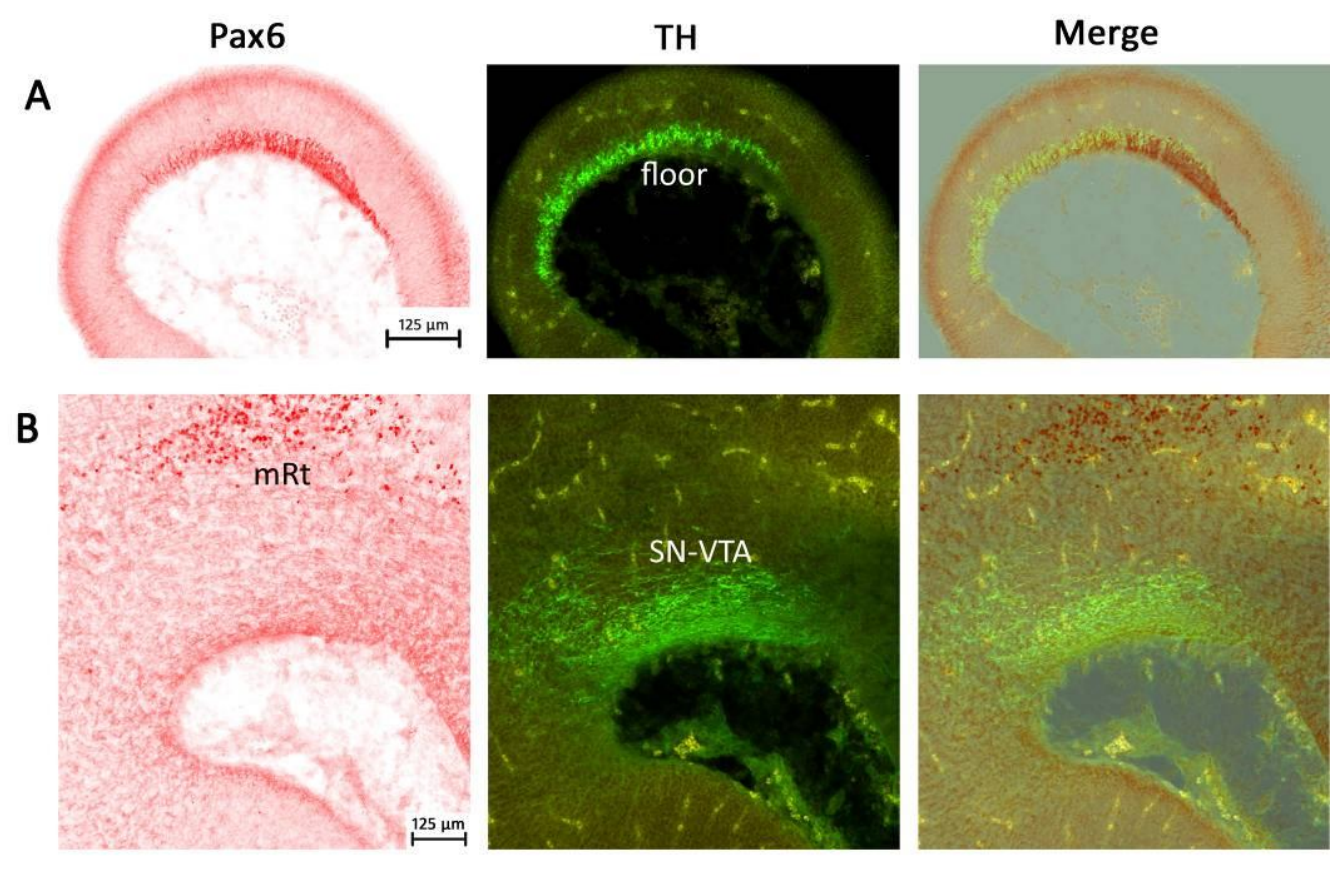

C
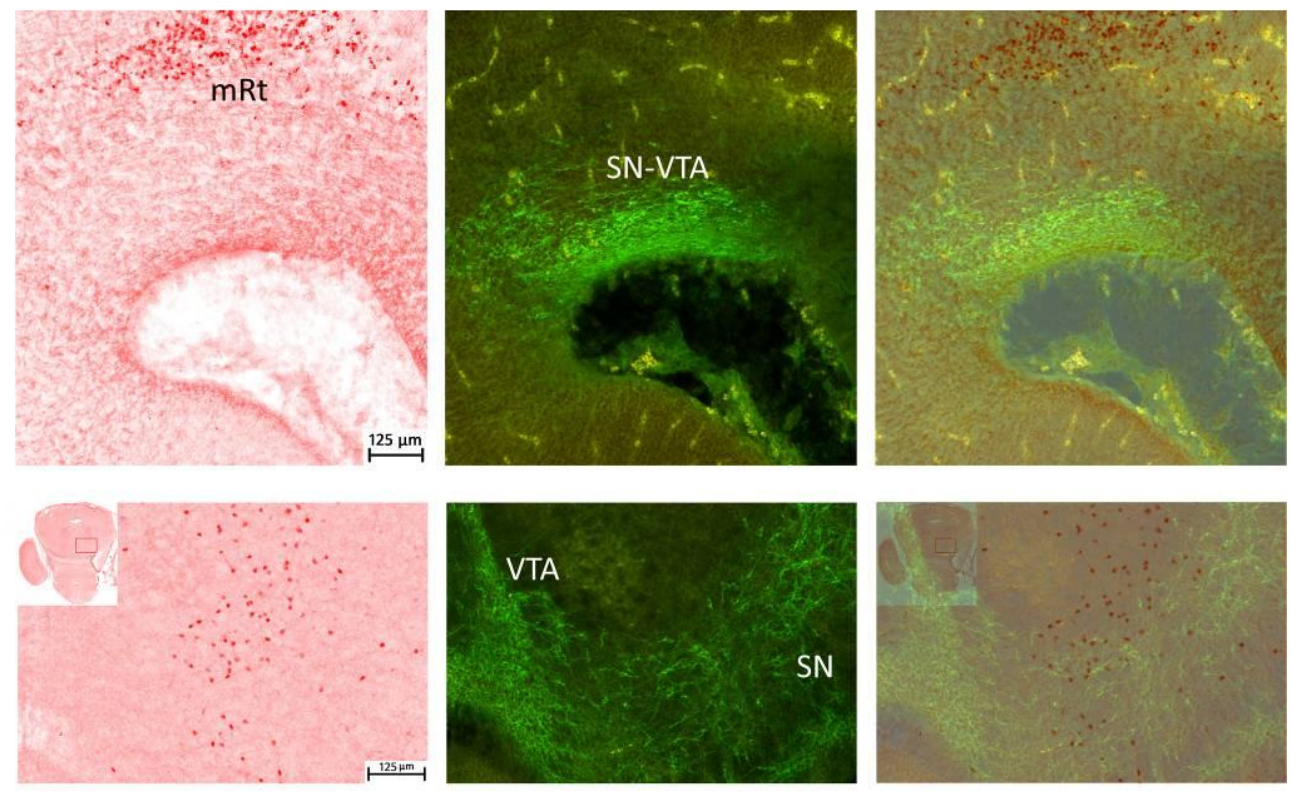

D
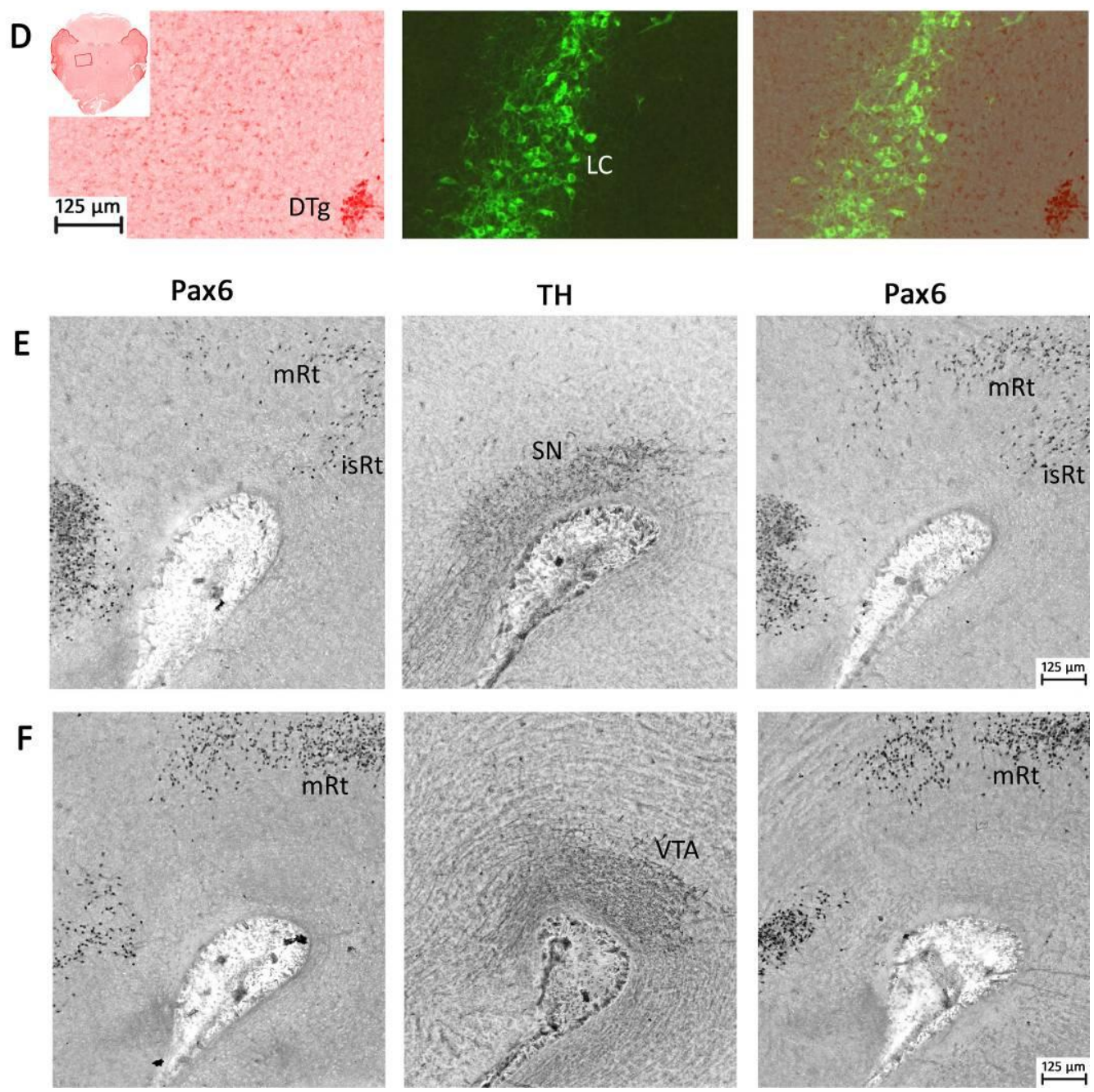
Fig. 9 Pax6 and TH expression in the embryonic and neonate brain. Double immunolabeling of Pax6 and TH in sagittal and coronal sections of the embryonic and postnatal brain showed that both proteins were expressed in the floor of E11 mesencephaon, but was not co-localized in the same cells in this location (A, sagittal). Pax6 was not expressed in TH-positive SN-VTA areas at E12 (B, sagittal), P1 (C, coronal), and not in TH-positive locus coeruleus at P1 (D, coronal). Three adjacent sagittal sections immunostained separately with Pax6 and TH antibody showed that Pax6 was not expressed in the TH positive regions of SN (E) and VTA (F) at E14.

\section{Quantification of Pax6 positive Cells in the adult brain}

The proportions of Pax6 positive cells in four regions of the adult brain, olfactory bulb, cortex, cerebellum, and the remaining areas excluding hippocampus, were measured by the Isotropic Fractionator method (Fig. 10) ( $\mathrm{n}=3$ each). The hippocampus was excluded because there are no Pax6 positive cells. Among DAPI labeled total cell population, Pax6 positive cells account for $10.7 \%$ in the olfactory bulb, $4.4 \%$ in the cortex, $72.8 \%$ in the cerebellum, and $3.4 \%$ in the remaining areas of the brain. Nuclei showing Pax6 and NeuN co-expression account for $4.3 \%$ of DAPI cells in the olfactory bulb, $1.7 \%$ in the cortex, $70.6 \%$ in the cerebellum, and $2.5 \%$ in the remaining areas. Among Pax6 positive cells, $40.7 \%$ of these cells in the olfactory bulb, $38.3 \%$ in the cortex, $97.1 \%$ in the cerebellum, and $73.9 \%$ in the remaining areas, express NeuN. 

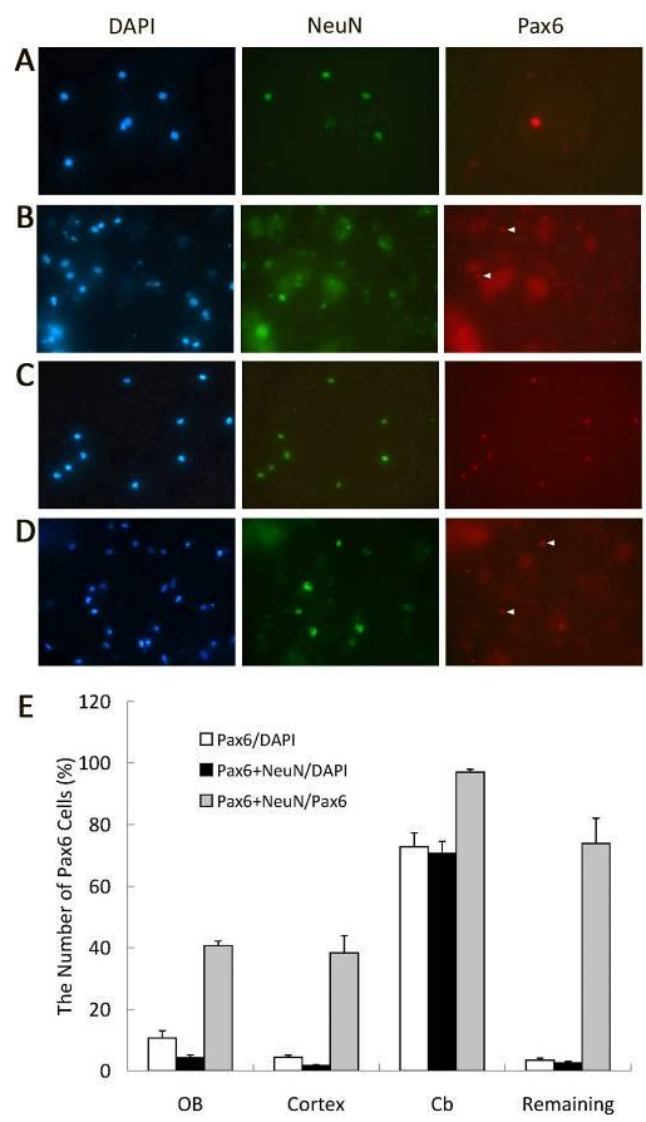

Fig. 10 The proportions of Pax6 positive cells in the different regions of the adult brain. The homogenates of the olfactory bulb (A), cortex (B), the cerebellum (C), and the remaining areas (D) are labeled with DAPI (blue), NeuN (green), and Pax6 (red, arrowhead). The percentages of NeuN and/or Pax6 positive cells are shown in E.

\section{Discussion}

Pax6 is a highly conserved transcription factor that is involved in regulation of neural proliferation and neuronal differentiation (Osumi et al. 2008). Numerous reports in many species, including human (Terzic and Saraga-Babic 1999; Mo and Zecevic 2008), mouse (Walther and Gruss 1991; Stoykova and Gruss 1994; Puelles et al. 2000), chick (Kawakami et al. 1997; Puelles et al. 2000), turtle (Metin et al. 2007), zebrafish (Hauptmann and Gerster 2000), lamprey (Osorio et al. 2005), and Xenopus (Moreno et al. 2008) have validated the evolutionary conservation in its expression in the brain. In the present study, the spatial and temporal expression patterns of Pax6 in the mouse brain were analyzed by immunostaining sagittal and coronal sections of embryonic (E11 to E17), neonate, and adult brains. We found that Pax6 is intensely expressed in the embryonic brain 
from the most rostral part, the telencephalon, to the caudal part, the rhombencephalon, and that the overall spatial patterns remain mostly the same throughout neurodevelopment until adulthood. Pax6 expression was first detected in the presumptive forebrain and hindbrain of the mouse at E8 (Walther and Gruss 1991), at the time when the neural tube is closing and the tube wall consists entirely of proliferating neuroepithelial cells (Osumi et al. 2008). At E10, the neural tube is regionalized to form the forebrain, midbrain, and hindbrain. The forebrain (prosencephalon) consists of the secondary prosencephalon and the diencephalon (Allen Brain Atlas Resources, data available from: http://www.brain-map.org). The secondary prosencephalon includes the preoptic area, prepeduncular (rostral) and peduncular (caudal) hypothalamus, and telencephalic vesicle. The diencephalon is divided into prosomere 1 (p1) (pretectum and pretectal tegmentum), p2 (thalamus and thalamic tegmentum, plus the habenula or epithalamus), and p3 (prethalamus and prethalamic tegmentum) (Puelles and Rubenstein 2003).

\section{Expression of Pax6 in the forebrain}

In the secondary prosencephalon, we found that Pax6 is expressed in nearly the whole layer of dorsolateral prosencephalic neuroepithelium at E11 until E13, and it is confined to the ventricular zone after E15. It is reported that the neural progenitor cells (neuroepithelial cells and radial glial cells) that divide at the ventricular surface strongly express Pax6 and exhibit astroglial properties (Osumi et al. 2008). Our data showed that Pax6 positive cells in the neuroepithelium and ventricular zone are negative for NeuN expression, thus these cells could be progenitor cells (with mitotic potential) but also could be glial cells or progenitor cells with astroglial properties. The expression levels of Pax6 appear to be essential for controlling the balance between neural stem cell self-renewal and neurogenesis, either reducing neocotical neural stem cell self-renewal and thereby resulting in excess early neurogenesis at a lower level, or promoting neurogenesis at the expense of the self-renewal at a higher level (Sansom et al. 2009). In the current study, the Pax6 expression gradient (high in the rostral-lateral area and low in the caudal-medial area) was consistent with the report by Muzio and Mallamaci (2003). The graded expression pattern of Pax6 in E11.5 mouse neocortex, (from a high level of expression at rostro-lateral areas to a low level of expression caudo-medial areas) indicates that Pax6 might contribute to the specification of rostral and lateral cortical domains, such as the primary motor cortex and the primary somatosensory 
cortex. Indeed, the absence of Pax6 in mice produced marked compression of rostral cortical areas at the level of the motor cortex (Muzio and Mallamaci 2003; Georgala et al. 2011). Moreover, it has ben shown that Pax6 plays a role in axon guidance between the cortex and subcortical cell groups; in Pax6 null mutants the majority of thalamocortical axons fail to enter the ventral telencephalon and those that do are unable to innervate their cortical targets in (Georgala et al. 2011).

Expression of Pax6 is maintained in the SVZ of the adult mouse cortex, and we found that $61.7 \%$ of the Pax6 positive cells are negative for NeuN, indicating their proliferative potential in the adult SVZ. Unlike to the situation in the embryonic brain, the remaining $38.3 \%$ of Pax6 positive neurons in the adult cortex co-express NeuN.

Pax6 is selectively required for the specification of several amygdaloid nuclei, (Tole et al. 2005). . The severity of the Pax6 null mutant phenotype depends on the level of Pax6 expression, and it is highly critical for development of the lateral and basolateral amygdaloid nuclei (with a high level of Pax6 expression), moderately important for the basomedial nucleus (low expression), and less important for the medial amygdaloid nucleus nuclei MeP and MeD (extremely low expression) (Tole et al. 2005).

In other areas of the prosencephalon, Pax6 expressing cells are mainly localized to post-mitotic cell groups in restricted domains: these include the taenia tecta, septum and diagonal domain, entopeduncular nucleus, piriform cortex, anterior olfactory nucleus, olfactory tubercle, preoptic area, hippocampus (dentate gyrus), and lateral hypothalamus. These expression patterns are mostly consistent with previous reports (Walther and Gruss 1991; Stoykova and Gruss 1994; Kawakami et al. 1997).

We found that expression of Pax6 in the taenia tecta and lateral hypothalamus emerged at E15, which is consistant with the fact that Stoykova and Gruss (1994) found this expression in the E13 embryo. Pax6 expression was mostly maintained in corresponding nuclei in the adult brain, except in the dentate gyrus, globus pallidus, and lateral nuclei (lateral posterior thalamic nucleus and laterodorsal thalamic nucleus). However, the intensity of Pax6 was much weaker in adult specimens. Pax6 expression is not observed in the adult dentate gyrus and globus pallidus, confirming the report by Stoykova and Gruss (1994), but this disagrees with a report of intense expression of Pax6 in proliferating precursors of the adult dentate gyrus (Nacher et al. (2005). 
In the diencephalon, we found that Pax6 is strongly expressed in the pretectum, thalamus (lateral and medial habenular nucleus), and prethalamus (pregeniculate nucleus, subgeniculate nucleus, zona incerta, and reticular thalamic nucleus) at E12, and all the expression persisted until adult. The expression borders of the pretectum and prethalamus coincide with prosomeric boundaries within the diencephalon and the boundary between diencephalon and mesencephalon, respectively (Walther and Gruss 1991; Stoykova and Gruss 1994). Pax6 appears to be important for this boundary formation, and null mutants have a deficit in posterior commissure axons, a landmark of the boundary between prosencephalon and mesencephalon (Mastick et al. 1997).

\section{Expression of Pax6 in the midbrain}

In the mesencephalon, we found that Pax6 was not expressed in the ventral tegmental area (VTA) and substantia nigra (SN) from E12 onwards, confirming the observations reported in the E12 mouse brain by Vitalis et al (2000). Pax6 expression was observed in the floor of the E11 mesencephalon, and TH expressing cells were not coincident with those that expressed Pax6 in this location. In the zebrafish ventral thalamus, Pax6 cells were found to have close spatiotemporal association with TH cells but they were not double-labeled (Wullimann and Rink 2001). However, in the mouse alar plate ventral thalamus (future zona incerta), Pax 6 cells indeed develop into dopaminergic neurons (Vitalis et al. 2000). In the Pax6 homologous deficient mutants, TH neurons in VTA were reduced by $75 \%$ at E11.5 and TH neurons in SN were accentuated at the p1-p2 border at E16.5 (Vitalis et al. 2000). Therefore, Pax6 expression in the floor of the mesencephalon (without co-localization of TH) at E11 seems to drive the production of TH neurons. This inductive action may be cell autonomous, in which case early Pax6 expression in the future TH cells would down-regulate before the TH phenotype appears in these cells. Alternatively, Pax6 cells might act inductively (cell to cell) on the development of TH cells in this region (i.e. in a non-cell autonomous manner) (Wullimann and Rink 2001). Pax6 is also necessary for correct pathfinding of the dopaminergic fibers along the medial forebrain bundle ventrally, because the homozygous Pax6-deficient mouse displayed a dorsally misrouted pathway of the fibers along the boundary between the pretectum and thalamus (Vitalis et al. 2000). The abnormal location and defective ascending pathway of TH neurons were thought to be non-cell autonomous defective since SN-VTA neurons do not express Pax6 at E12 but the dorsorostrally deflected SN-VTA 
projections cross regions that do express Pax6 (Georgala et al. 2011).

Pax6 is also expressed in the deep mesencephalic nucleus (DpMe) in the E12.5 embryo (Vitalis et al. 2000) and the young adult mouse (Stoykova and Gruss 1994), and in the mesencephalic tegmentum and differentiating SN at E13 (Stoykova and Gruss 1994). We found that Pax6 is expressed in a similar area in the mesencephalic tegmentum throughout development. The term DpMe has recently been abandoned in the most widely cited rodent brain atlas, and it is designated as the mesencephalic reticular formation (mRt) (Paxinos and Watson 2007). Likewise, other parts of the reticular formation were named isRt in the isthmus and r1Rt in rhombomere 1 (r1) according to their neuromeric location (Paxinos and Watson 2007; Ashwell and Paxinos 2008). The present study did not reveal Pax6 expression in the mesencephalic tegmentum and differentiating substatia nigra, at variance with results reported by Stoykova and Gruss (1994).

\section{Expression of Pax6 in the hindbrain}

New gene expression data have forced major changes in nomenclature regarding the developing and adult hindbrain (Puelles et al. 2007). Gene expression reveals the presence of an isthmic region between the midbrain and the first rhombomere (Watson 2010), and the remainder of the axial hindbrain should be termed the rhombencephalon (rhombomeres 1-11) (Puelles et al. 2007). As a consequence, the old terms metencephalon and mylencephalon should now be abandoned. The old metencephalon corresponds to the isthmus and rhombomeres 1 and 2 and the old myelencephalon corresponds to rhombomeres 3-11. In the adult brain, the terms pons and medulla oblongata have been used to subdivide the hindbrain, but the variable size of the basilar pons in mammals makes this usage very unhelpful. In traditional human brain terminology, the term pons represents the part of the hind brain from the midbrain to the seventh rhombomere, whereas $n$ the mouse, the basilar pons is located only in rhombomeres 3 and 4 (Puelles et al. 2007). Finally, it should be noted that the cerebellum in mammals arises from the isthmus and the first rhombomere (Sillitoe et al. 2012).

A previous study (Walther and Gruss 1991) did not detect Pax6 expression rhombencephalon until E15.5, but we found expression in the nucleus of the lateral lemniscus as early as E12. Pax6 expression is clearly seen in the rhombic lip and its diversely distributed derivatives in the 
hindbrain throughout development, including the major precerebellar nuclei (the pontine nuclei, reticulotegmental nucleus of the pons, lateral reticular nucleus, inferior olivary nucleus, external cuneate nucleus, and motor trigeminal nucleus, parvicellular part), hindbrain sensory nuclei (the cochlear nuclei, vestibular nuclei, and nucleus X), hindbrain monoamine nuclei (the median raphe nucleus, dorsal raphe nucleus, and locus coeruleus), and others (dorsal nucleus of the lateral lemniscus, paralemniscal nucleus, laterodorsal tegmental nucleus, gigantocellular reticular nucleus, and linear nucleus). The linear nucleus of the hindbrain is a rostrodorsal extension of the lateral reticular nucleus (Fu et al. 2009). The expression pattern of Pax6 in the embryonic hindbrain is maintained in the adult brain. Of the adult total cerebellar cells, $70.6 \%$ express Pax6 and $97.1 \%$ of Pax6 positive cells co-express NeuN.

Pax6 is expressed in the upper rhombic lip derived external granular layer of the developing cerebellum and maintained in the adult cerebellar granule cells. It is critical for the morphogenesis of the entire cerebellum because a mutation in Pax6 results in not only a decreased neuronal differentiation and an increased proliferation of granule cell precursors in vitro, but also a disruption of signaling from the external granular layer of developing cerebellum to Purkinje cells in vivo (Swanson et al. 2005).

Pax6 is expressed in the lower rhombic lip derived neurons, mossy fiber neurons (the pontine gray, reticulotegmental nucleus of the pons, lateral reticular nucleus, external cuneate nucleus) and climbing fiber neurons (inferior olivary nucleus). The mossy fiber neurons project to the cerebellar granule cells, which are characterized by expression of the proneural bHLH transcription factor, Math1 (Landsberg et al. 2005). Math1 expression is also detected in Pax6 positive nuclei such as the pontine nuclei, dorsal nucleus of the lateral lemniscus, laterodorsal tegmental nucleus, and granule cell precursors of external granular layer of developing cerebellum (Machold and Fishell 2005). It has been reported that Pax6 could bind to particular Math1 regulatory sequences in vitro and exert its regulatory effects on Math1 expression in the lower rhombic lip (Hufnagel et al. 2007).

Another characteristic feature of Pax6 expressing nuclei is that most of them express Wnt1, one of the canonical Wnt genes. Robust expression of Wnt1 was observed in the major precerebellar nuclei, hindbrain sensory nuclei, and hindbrain monoamine nuclei (Fu et al. 2011). Wnt1 emanates from the isthmic organizer and is required for the midbrain development and cerebellar 
morphogenesis (Liu and Joyner 2001; Schuller and Rowitch 2007). It functions to stabilize its

intracellular signaling molecule $\beta$-catenin which is required for cerebellar morphogenesis. Several reports demonstrated that conditional or sustaining expression of $\beta$-catenin could result in expansion of Pax6 expression in the developing neocortex (Backman et al. 2005; Wrobel et al. 2007), maintenance of the proliferative state, and repression of differentiation of neural progenitor cells (Wrobel et al. 2007; Wexler et al. 2009). Pax6 has not been reported as a direct transcriptional target of $\beta$-catenin in the brain, but Pax6 is found to down-regulate canonical Wnt signaling in the presumptive lens ectoderm via directly controling expression of several Wnt inhibitors such as Sfrp1, Sfrp2, and Dkk1 in the presumptive lens (Machon et al. 2010). Therefore, the roles of Wnt1- $\beta$-catenin system in the development of the cerebellum and the nuclei of the hindbrain and remain to be elucidated further.

Acknowledgments We thank Dr. Huazheng Liang, Dr. Emma Schofield, and Mr Hua Zhao for technical support. This work was supported by the Christopher and Dana Reeve Foundation and an Australia Fellowship awarded to Professor George Paxinos by the National Health and Medical Research Council (NHMRC) (466028).

\section{References}

Ashwell KW, Paxinos G (2008) Atlas of the developing rat nervous system. 3rd edn. Elsevier Academic Press, San Diego

Backman M, Machon O, Mygland L, van den Bout CJ, Zhong W, Taketo MM, Krauss S (2005) Effects of canonical Wnt signaling on dorso-ventral specification of the mouse telencephalon. Developmental biology 279 (1):155-168. doi:10.1016/j.ydbio.2004.12.010

Burri M, Tromvoukis Y, Bopp D, Frigerio G, Noll M (1989) Conservation of the paired domain in metazoans and its structure in three isolated human genes. EMBO J 8 (4):1183-1190

Callaerts P, Halder G, Gehring WJ (1997) PAX-6 in development and evolution. Annu Rev Neurosci 20:483-532. doi:10.1146/annurev.neuro.20.1.483

Franklin K, Paxinos G (2008) The mouse brain in stereotaxic coordinates. 3rd edn. Academic Press, San Diego

Fu Y, Tvrdik P, Makki N, Palombi O, Machold R, Paxinos G, Watson C (2009) The precerebellar linear nucleus in the mouse defined by connections, immunohistochemistry, and gene expression. Brain Res 1271:49-59. doi:10.1016/j.brainres.2009.02.068

Fu Y, Tvrdik P, Makki N, Paxinos G, Watson C (2011) Precerebellar cell groups in the hindbrain of the mouse defined by retrograde tracing and correlated with cumulative Wnt1-cre genetic labeling. Cerebellum 10 (3):570-584. doi:10.1007/s12311-011-0266-1 
Georgala PA, Carr CB, Price DJ (2011) The role of Pax6 in forebrain development. Developmental Neurobiology 71 (8):690-709. doi:10.1002/dneu.20895

Hauptmann G, Gerster T (2000) Regulatory gene expression patterns reveal transverse and longitudinal subdivisions of the embryonic zebrafish forebrain. Mech Dev 91 (1-2):105-118

Herculano-Houzel S, Lent R (2005) Isotropic fractionator: a simple, rapid method for the quantification of total cell and neuron numbers in the brain. The Journal of neuroscience : the official journal of the Society for Neuroscience 25 (10):2518-2521. doi:10.1523/JNEUROSCI.4526-04.2005

Hufnagel RB, Riesenberg AN, Saul SM, Brown NL (2007) Conserved regulation of Math5 and Math1 revealed by Math5-GFP transgenes. Molecular and cellular neurosciences 36 (4):435-448. doi:10.1016/j.mcn.2007.08.006

Kawakami A, Kimura-Kawakami M, Nomura T, Fujisawa H (1997) Distributions of PAX6 and PAX7 proteins suggest their involvement in both early and late phases of chick brain development. Mech Dev 66 (1-2):119-130

Landsberg RL, Awatramani RB, Hunter NL, Farago AF, DiPietrantonio HJ, Rodriguez CI, Dymecki SM (2005) Hindbrain rhombic lip is comprised of discrete progenitor cell populations allocated by Pax6. Neuron 48 (6):933-947. doi:10.1016/j.neuron.2005.11.031

Liang H, Paxinos G, Watson C (2010) Projections from the brain to the spinal cord in the mouse. Brain Structure and Function 215 (3-4):159-186. doi:10.1007/s00429-010-0281-x

Liu A, Joyner AL (2001) Early anterior/posterior patterning of the midbrain and cerebellum. Annu Rev Neurosci 24:869-896. doi:10.1146/annurev.neuro.24.1.869

Machold R, Fishell G (2005) Math1 is expressed in temporally discrete pools of cerebellar rhombic-lip neural progenitors. Neuron 48 (1):17-24. doi:10.1016/j.neuron.2005.08.028

Machon O, Kreslova J, Ruzickova J, Vacik T, Klimova L, Fujimura N, Lachova J, Kozmik Z (2010) Lens morphogenesis is dependent on Pax6-mediated inhibition of the canonical Wnt/betacatenin signaling in the lens surface ectoderm. Genesis 48 (2):86-95. doi:10.1002/dvg.20583

Manuel M, Price D (2005) Role of Pax6 in forebrain regionalization. Brain Research Bulletin 66 (46):387-393. doi:10.1016/j.brainresbull.2005.02.006

Mastick GS, Davis NM, Andrew GL, Easter SS, Jr. (1997) Pax-6 functions in boundary formation and axon guidance in the embryonic mouse forebrain. Development 124 (10):1985-1997

Metin C, Alvarez C, Moudoux D, Vitalis T, Pieau C, Molnar Z (2007) Conserved pattern of tangential neuronal migration during forebrain development. Development 134 (15):2815-2827. doi:10.1242/dev.02869

Mo Z, Zecevic N (2008) Is Pax6 critical for neurogenesis in the human fetal brain? Cereb Cortex 18 (6):1455-1465. doi:10.1093/cercor/bhm181

Moreno N, Rétaux S, González A (2008) Spatio-temporal expression of Pax6 in Xenopus forebrain. Brain Research 1239:92-99. doi:10.1016/j.brainres.2008.08.052

Muzio L, Mallamaci A (2003) Emx1, emx2 and pax6 in specification, regionalization and arealization of the cerebral cortex. Cereb Cortex 13 (6):641-647

Nacher J, Varea E, Blasco-Ibanez JM, Castillo-Gomez E, Crespo C, Martinez-Guijarro FJ, McEwen BS (2005) Expression of the transcription factor Pax 6 in the adult rat dentate gyrus. J Neurosci Res 81 (6):753-761. doi:10.1002/jnr.20596

Noll M (1993) Evolution and role of Pax genes. Curr Opin Genet Dev 3 (4):595-605

Osorio J, Mazan S, Retaux S (2005) Organisation of the lamprey (Lampetra fluviatilis) embryonic brain: insights from LIM-homeodomain, Pax and hedgehog genes. Developmental biology 
288 (1):100-112. doi:10.1016/j.ydbio.2005.08.042

Osumi N (2001) The role of Pax6 in brain patterning. Tohoku J Exp Med 193 (3):163-174

Osumi N, Shinohara H, Numayama-Tsuruta K, Maekawa M (2008) Concise review: Pax6 transcription factor contributes to both embryonic and adult neurogenesis as a multifunctional regulator. Stem Cells 26 (7):1663-1672. doi:10.1634/stemcells.2007-0884

Paxinos G, Halliday G, Watson C, Koutcherov Y, Wang H (2007) Atlas of the developing mouse brain at E17.5, P0, and P6. Elsevier Academic Press, San Diego

Paxinos G, Watson C (2007) The rat brain in stereotaxic coordinates. 6th edn. Elsevier Academic Press, San Diego

Pritz MB, Ruan YW (2009) PAX6 immunoreactivity in the diencephalon and midbrain of alligator during early development. Brain Behav Evol 73 (1):1-15. doi:10.1159/000195695

Puelles L, Kuwana E, Puelles E, Bulfone A, Shimamura K, Keleher J, Smiga S, Rubenstein JL (2000) Pallial and subpallial derivatives in the embryonic chick and mouse telencephalon, traced by the expression of the genes Dlx-2, Emx-1, Nkx-2.1, Pax-6, and Tbr-1. J Comp Neurol 424 (3):409-438

Puelles L, Martinez-de-la-Torre M, Paxinos G, Watson C, Martinez S (2007) The Chick Brain in Stereotaxic Coordinates. An atlas featuring neuromeres and mammalian homologies. Elsevier Academic Press, San Diego

Puelles L, Rubenstein JL (2003) Forebrain gene expression domains and the evolving prosomeric model. Trends Neurosci 26 (9):469-476

Sansom SN, Griffiths DS, Faedo A, Kleinjan DJ, Ruan Y, Smith J, van Heyningen V, Rubenstein JL, Livesey FJ (2009) The level of the transcription factor Pax6 is essential for controlling the balance between neural stem cell self-renewal and neurogenesis. PLoS genetics 5 (6):e1000511. doi:10.1371/journal.pgen.1000511

Schubert FR, Lumsden A (2005) Transcriptional control of early tract formation in the embryonic chick midbrain. Development 132 (8):1785-1793. doi:10.1242/dev.01731

Schuller U, Rowitch DH (2007) Beta-catenin function is required for cerebellar morphogenesis. Brain Res 1140:161-169. doi:10.1016/j.brainres.2006.05.105

Sillitoe R, Fu Y, Watson C (2012) Cerebellum. In: Watson C, Paxinos G, Puelles L (eds) The mouse nervous system. Elsevier Academic Press, San Diego, pp 360-396

Spitere K, Toulouse A, O'Sullivan DB, Sullivan AM (2008) TAT-PAX6 protein transduction in neural progenitor cells: a novel approach for generation of dopaminergic neurones in vitro. Brain Res 1208:25-34. doi:10.1016/j.brainres.2008.02.065

Stoykova A, Gruss P (1994) Roles of Pax-genes in developing and adult brain as suggested by expression patterns. J Neurosci 14 (3 Pt 2):1395-1412

Swanson DJ, Tong Y, Goldowitz D (2005) Disruption of cerebellar granule cell development in the Pax6 mutant, Sey mouse. Brain research Developmental brain research 160 (2):176-193. doi:10.1016/j.devbrainres.2005.09.005

Takahashi M, Osumi N (2011) Pax6 regulates boundary-cell specification in the rat hindbrain. Mechanisms of Development. doi:10.1016/j.mod.2011.04.001

Terzic J, Saraga-Babic M (1999) Expression pattern of PAX3 and PAX6 genes during human embryogenesis. The International journal of developmental biology 43 (6):501-508

Tole S, Remedios R, Saha B, Stoykova A (2005) Selective requirement of Pax6, but not Emx2, in the specification and development of several nuclei of the amygdaloid complex. J Neurosci 25 
(10):2753-2760. doi:10.1523/JNEUROSCI.3014-04.2005

Vitalis T, Cases O, Engelkamp D, Verney C, Price DJ (2000) Defect of tyrosine hydroxylaseimmunoreactive neurons in the brains of mice lacking the transcription factor Pax6. J Neurosci 20 (17):6501-6516. doi:20/17/6501 [pii]

Walther C, Gruss P (1991) Pax-6, a murine paired box gene, is expressed in the developing CNS. Development 113 (4):1435-1449

Watson C (2010) The presumptive isthmic region in a mouse as defined by fgf8 expression. Brain Behav Evol 75:15

Wexler EM, Paucer A, Kornblum HI, Palmer TD, Geschwind DH (2009) Endogenous Wnt signaling maintains neural progenitor cell potency. Stem Cells 27 (5):1130-1141. doi:10.1002/stem.36

Wrobel CN, Mutch CA, Swaminathan S, Taketo MM, Chenn A (2007) Persistent expression of stabilized beta-catenin delays maturation of radial glial cells into intermediate progenitors. Developmental biology 309 (2):285-297. doi:10.1016/j.ydbio.2007.07.013

Wullimann MF, Rink E (2001) Detailed immunohistology of Pax6 protein and tyrosine hydroxylase in the early zebrafish brain suggests role of Pax6 gene in development of dopaminergic diencephalic neurons. Brain research Developmental brain research 131 (1-2):173-191

Yamada K, Semba R, Ding X, Ma N, Nagahama M (2005) Discrimination of cell nuclei in early Sphase, mid-to-late S-phase, and G(2)/M-phase by sequential administration of 5-bromo-2'deoxyuridine and 5-chloro-2'-deoxyuridine. J Histochem Cytochem 53 (11):1365-1370. doi:10.1369/jhc.4A6601.2005

Zhang X, Huang CT, Chen J, Pankratz MT, Xi J, Li J, ..., Zhang S-C (2010) Pax6 is a human neuroectoderm cell fate determinant. Cell Stem Cell 7 (1):90-100. doi:10.1016/j.stem.2010.04.017 